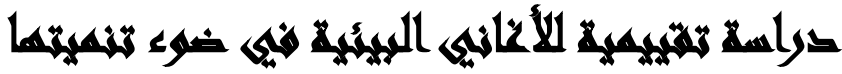

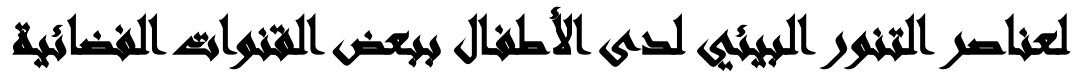

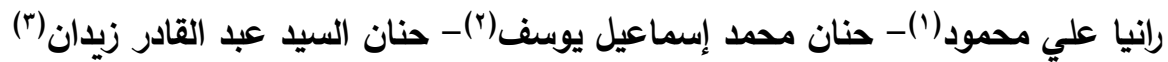

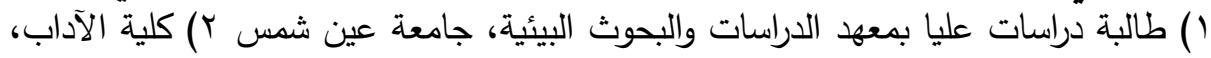

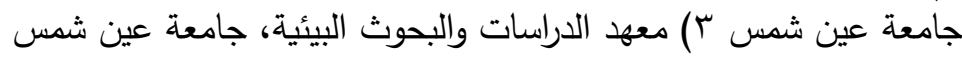

\section{المستخليف}

هدف البحث إلى تعرف فاعلية الأغانى البيئية فى تتمية التتور البيئى لتلاميذ الصف بكف

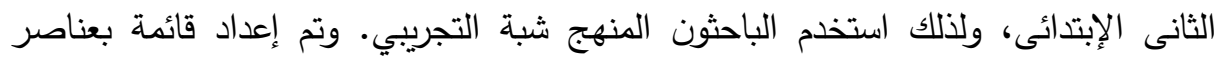

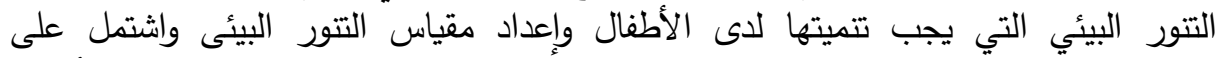

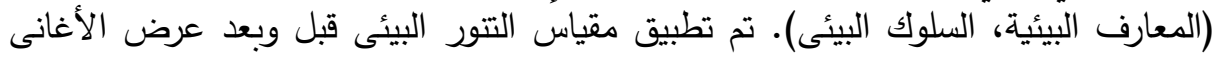
البيئية على مجموعة البحث وعددها (• ـ البئهة مفردة.

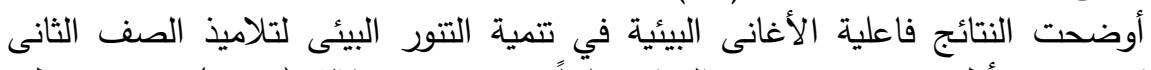

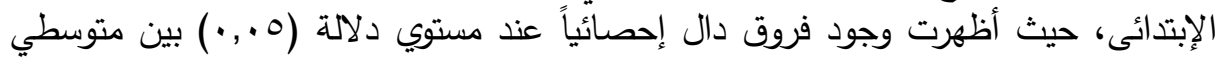

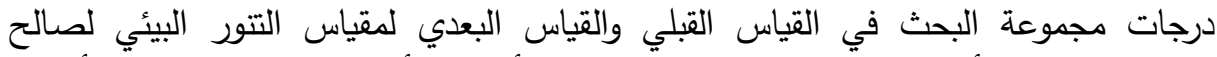

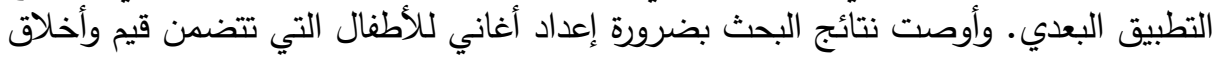

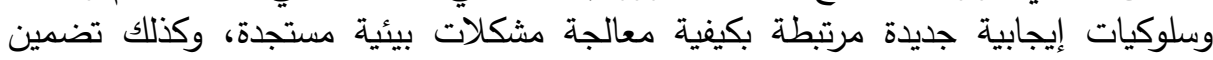

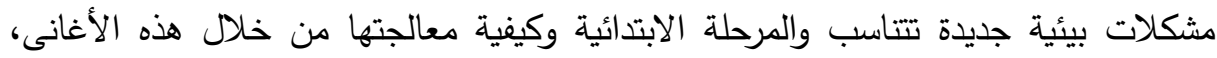
التكامل بين المؤسسات التعليمية والإعلامية فى دمج وتضمين الإلية الأغانى البيئبة فى المناهج وبرامج الأطفال التليفزيونية.

\section{rasill}

إن الإهتمام بالبيئة وصيانتها على كافة المستويات من كل ما يحدث بها من مخاطر

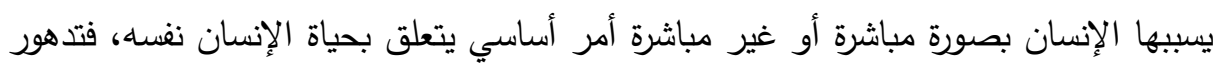

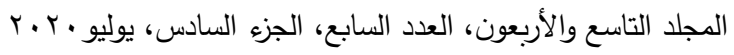

$$
\begin{aligned}
& \text { الترقيم الدولي 0826- ISSN 1110 }
\end{aligned}
$$


البيئة يعني تدمير حياة الإنسان، والمحافظة على البيئة يعني الرخاء والتقدم لحياة الإنسان في

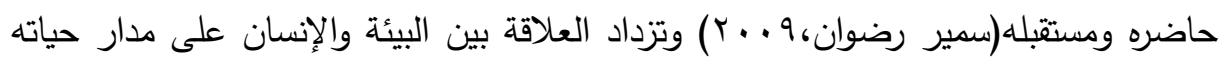

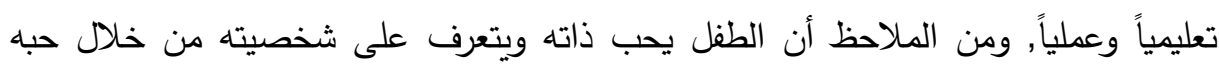
واحترامه لبيئته؛ لأنه بذلك يشعر أنه إمتداد للبيئة, وأنه مسئول عنها. (محمود الزيادى,

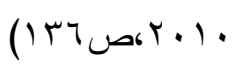

وبالرغم من أن القوانين والتشريعات البيئية لا يمكن إنكار دورها في صيانة البيئة

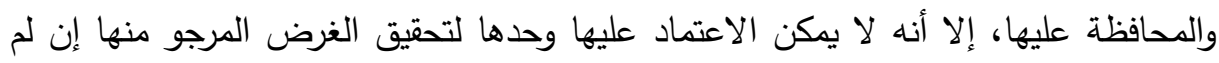

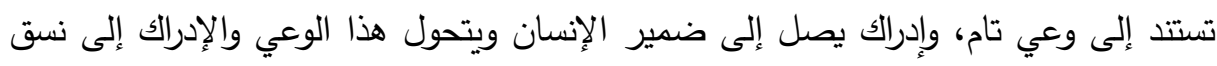
قيمي يحافظ على النظام البيئي والمكونات البيئية (Russell, T. and Rain R. 1967), ولقد أصبحت وسائل الإعلام جزء لا يتجزأ من عمليتي التربية والتثقيف كما أنها تمثل حجر الزاوية في التعليم غير النظامي، ويتضح ذلك من العلاقة بين الإعلام والتربية البيئية إذ يعمل

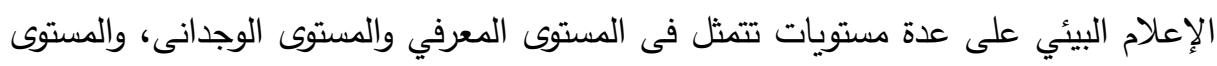
السلوكي، والمستوى المهاري، ويسعى الإعلام البيئي إلى إكساب الطفل المعارف والمفاهيم المئي

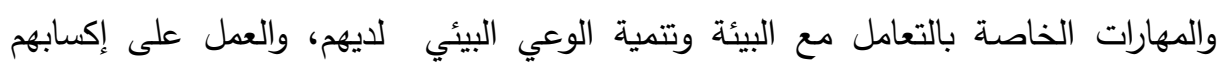
الاتجاهات الإيجابية والسلوكيات الرشيدة نحو البيئة والعمل على التحفيز للمشاركة الإيجابية

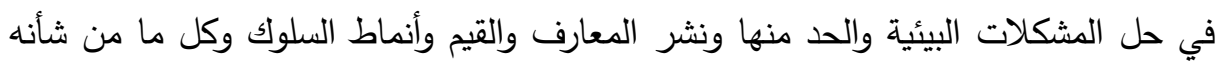

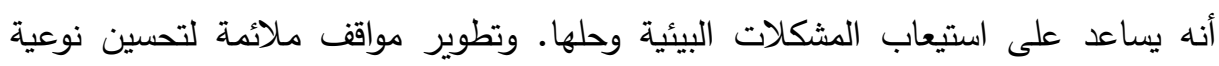

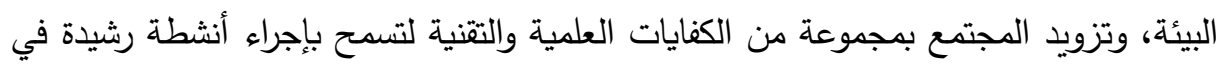

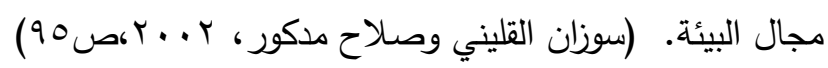

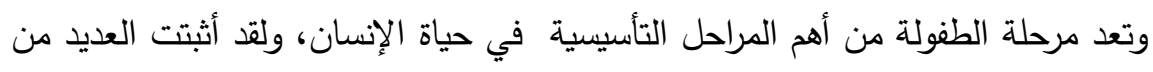

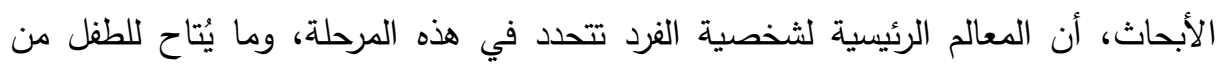

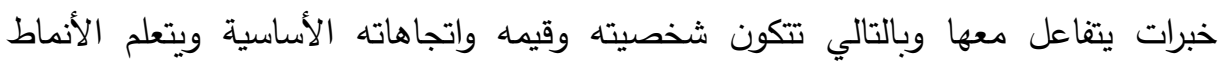
178

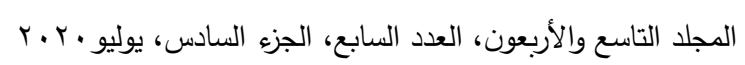

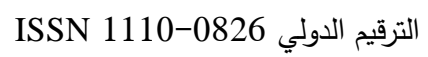




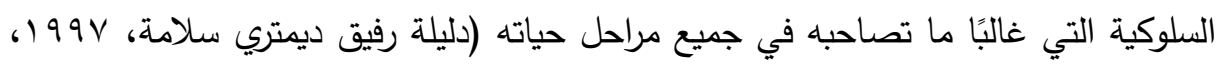

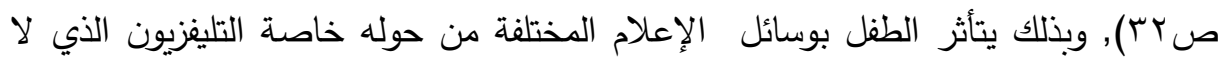
يمكن أن يغفل أحد أثره في حياة أطفالنا وفي تتشئتهم مما دعا الباحثين في مجال الإعلام إلى تسميته بالأب الثالث في حياة الأطفال فطفل اليوم ينشئه ثلاثة آباءهم (الأم والأب

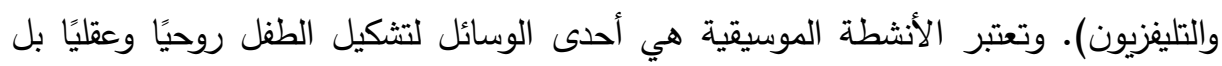

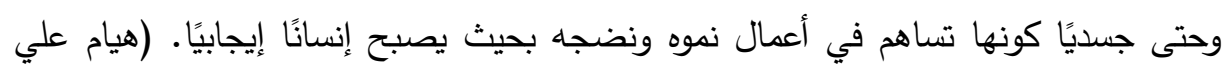

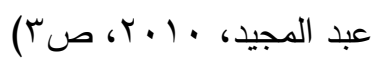
وترتبط الموسيقى والأغاني بالتربية فكلاهما يعتمد على الآخر في تطور الفرد وبناء شخصيته إلى الحد الذي يمكنه من المشاركة والمساهمة في الثقافة والحضارة التي يكتسبها, فالبرامج التعليمية التي تعتمد على إكساب الطفل بكثير من المفاهيم والإتجاهات المقبولة

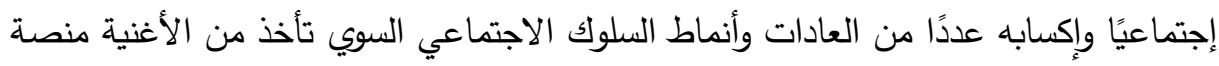

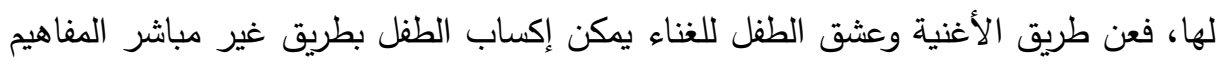

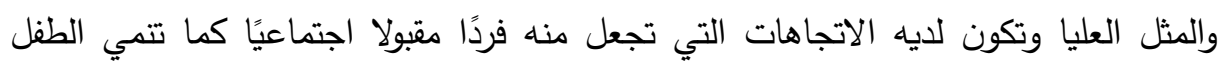

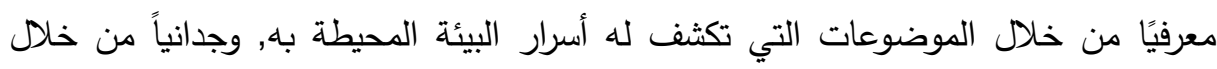
الاهتمام بالجوانب البيئية ومعالجتها من خلال تتور الطفل بمجموعة من المعارف والسلوكيات.

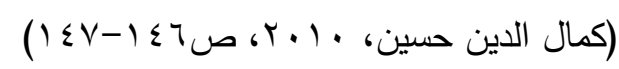
ويهدف التتور البيئى إلى إعداد الطفل كى يصبح مواطناً متنور بيئياً، يفه كيف تعمل صلئ النظم الطبيعية والبشرية وتتصل ببعضها البعض، يرتبط هذا الفهم بالإتجاهات والخبرات

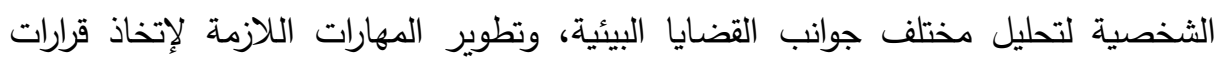
مسئولة على أساس الإعتبارات العلمية والثقافية والأخلاقية، ولذلك كان الإعتراف بالتتور

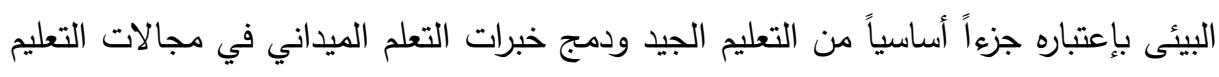
النظامى وغير النظامى في كل مرحلة من المراحل العمرية. (Bennett, Cindy, 2014)

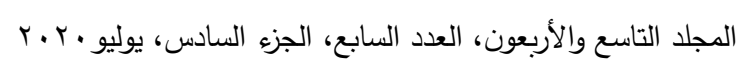

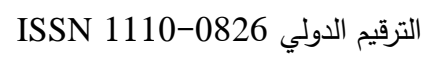


فالتتور البيئى عملية يتم من خلالها إعداد مواطن لديه القدرة على ضبط الذات والبعد عن

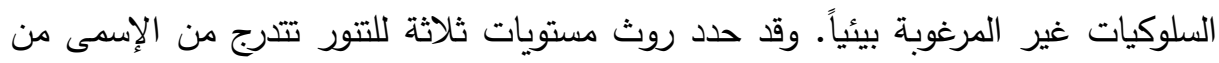
خلال تعرف بعض المصطلحات الأساسية إلى الوظيفي لفهم الطبيعة والتفاعل بين الأنسان

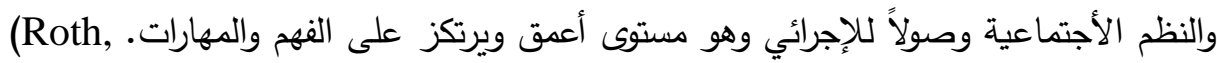

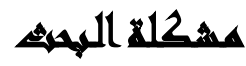

توصل الباحثون لمشكله الدراسه من خلال:

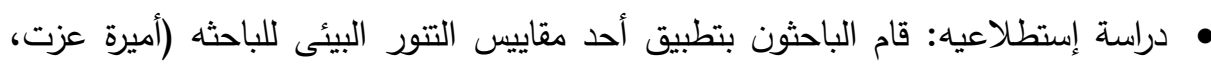
10 ا ب) على مجموعة من التلاميذ المرحلة الابتدائية بمدرسة ابن سينا الإبتدائيه المشتركه

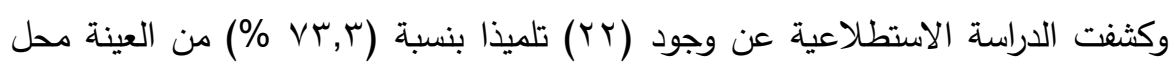

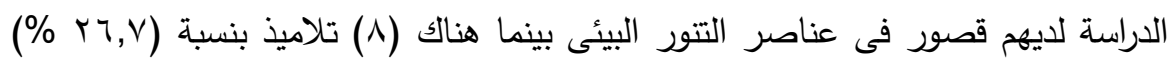
ليس لديهم قصور في التتور البيئي. هالدراسات السابقه: بدأ الإحساس بالمشكلة من خلإل معرفة الباحثون بنتائج الكثير

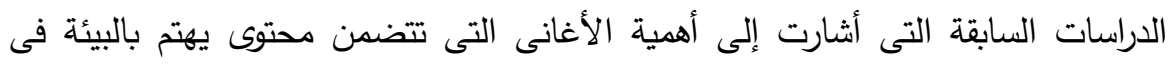
تتمية بعض الجوانب البيئية إذا أحسن استخدامها, ومنها:

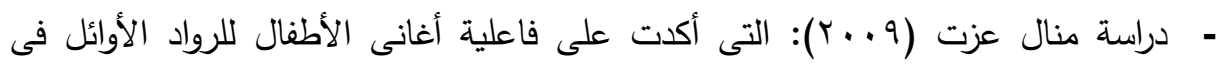
التغيير الإيجابى الواضح فى تتمية بعض القيم التربوية لاى الأطفال.

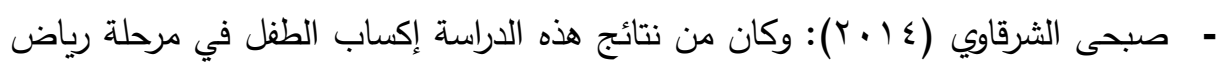

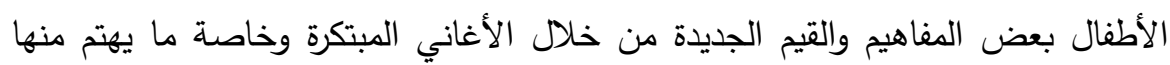
بالطبيعة. 
- زهية يسعد (T ( ب): والتي أثبتت أن الأغاني التليفزيونية الموجهة للأطفال تؤثر فيهم بنسبة وصلت إلى •^ ٪ ب بينت الدراسة أن الطفل في هذه المرحلة العمرية الصغرى يكون

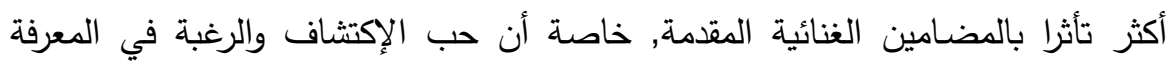
تكون في أوجها خلال هذه المرحلة من حياة الطفل.

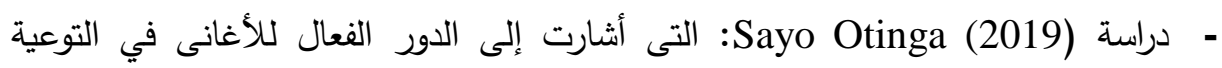
بقضايا البيئة والحفاظ عليها انطلاقا من تثكيل المفاهيم المرتبطة بالبيئة وتتمية السلوك لئك

$$
\text { البيئى الإيجابى لدى أطفال المرحلة المتوسطة. }
$$

ولهذا تعتبر أغانى الأطفال جديرة بالدراسة للتعرف على محتوى هذه الأغانى ومانى الألى يقدم

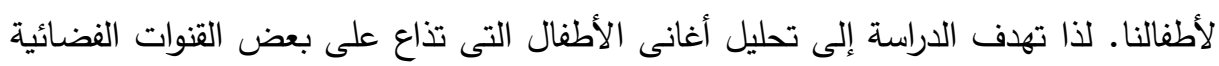

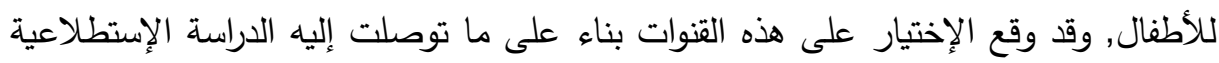

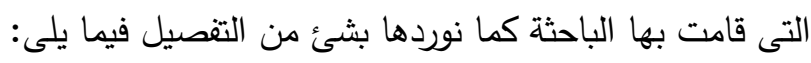
• دراسة استطلاعية بشأن القنوات الأكثر متابعة : من خلال دراسة استطلاعية قامت بهات بهات بهات

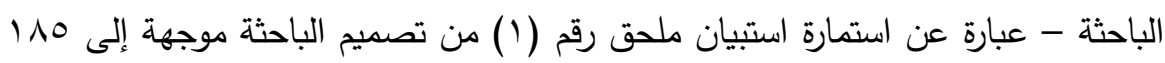

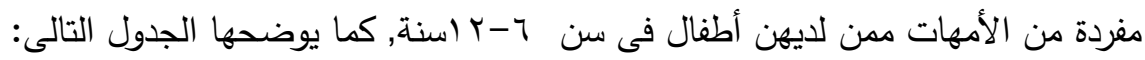

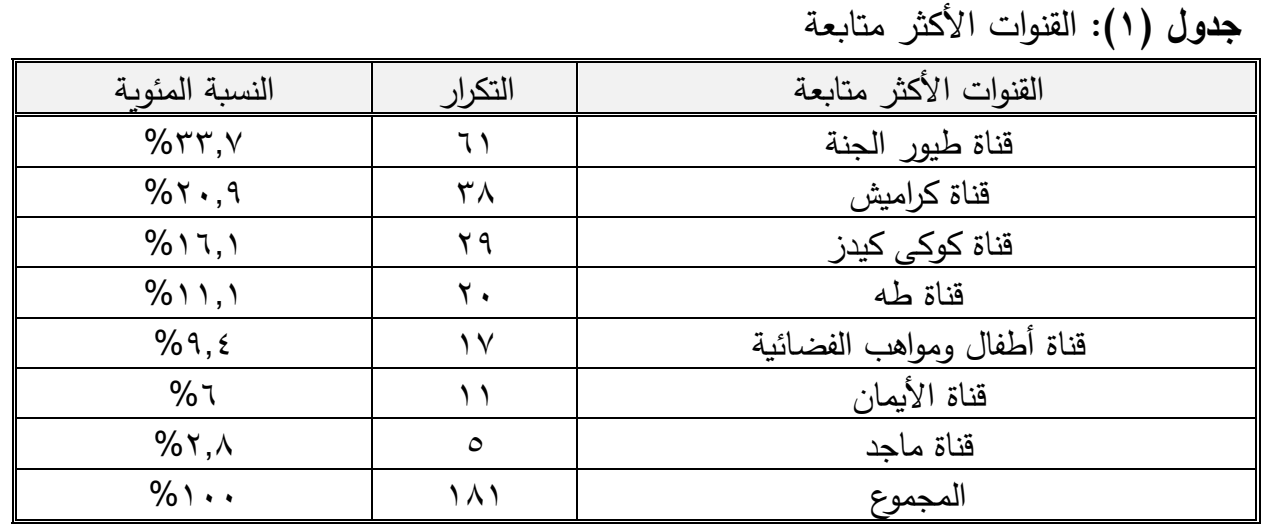




$$
\begin{aligned}
& \text { مجلة العلوم البيئية } \\
& \text { معهد الدراسات والبحوث البيئية - جامعة عين شمس لئس } \\
& \text { رانيا علي محمود وآخرون }
\end{aligned}
$$

يوضح الجدول السابق أن Yr,V\% من الأطفال الذين يتابعون بانتظام اختارو قناة

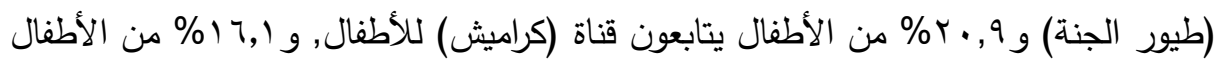

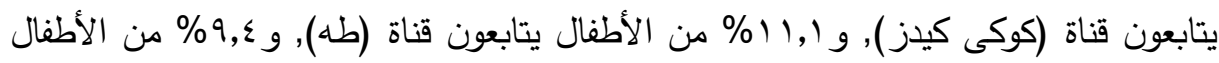

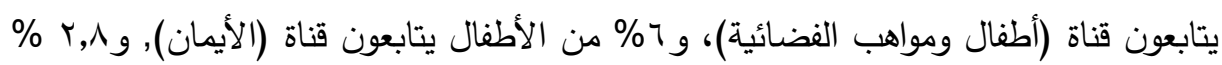
من الأطفال يتابعون قناة (ماجد).

وهذه القنوات متخصصة فى عرض محتوى يخص الأطفال ومنها الأغانى بصفة عامة, وتقوم بعرض مجموعة من أغانى الأطفال خلال اليوم وذلك لضمان الوقوف على لإنى جميع أغانى

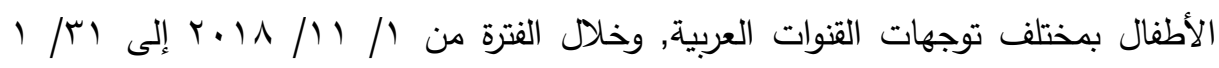

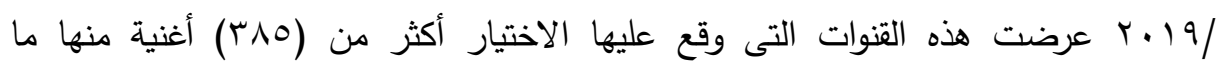
يتضمن بعض الجوانب التى تخص البيئة ومنها ما لم يتضمن, قامت الباحثة باختيار (ع (Y) أغنية من هذه الأغانى المعروضة خلال تلك الفترة والتى تتوافق مع المعارف والسلوكيات التى لتى لتصني

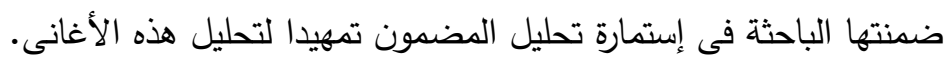

\section{أسرئل المبهم}

للتصدي لهذه المشكلة يحاول البحث الحالي الإجابة عن السؤال الرئيس التالى:

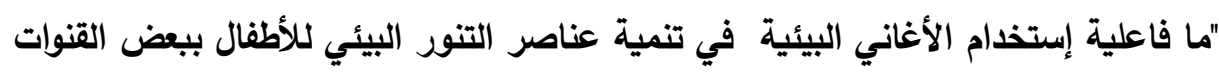
الفضائية؟" ماعبه

ويتفرع عن هذا السؤال الأسئلة الفرعية التالية:

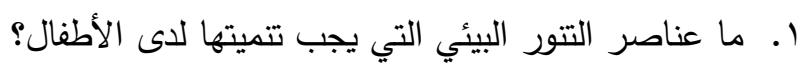

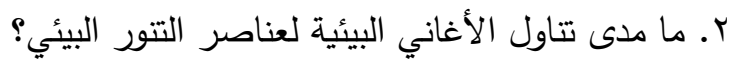

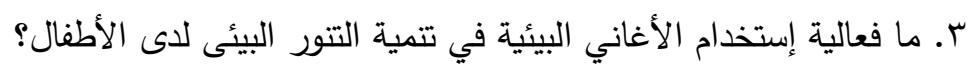




$$
\begin{aligned}
& \text { مجلة العلوم البيئية } \\
& \text { معهد الدراسات والبحوث البيئية - جامعة عين شمس لئه } \\
& \text { رانيا علي محمود وآخرون }
\end{aligned}
$$

\section{هبروض المهنش}

الفرض الرئيس: "يوجد فرق دال إحصائياً بين متوسطي درجات أطفال المجموعة التجريبية في التطبيق القبلي والبعدي فى مقياس التنور البيئي ككل لصالح التطبيق البعدي". الفرضان الفرعيان: • يوجد فرق دال إحصائياً بين متوسطي درجات أطفال المجموعة التجريبية في التطبيق القبلي والبعدي في اختبار المعارف البيئية ككل لصالح التطبيق البعدي.

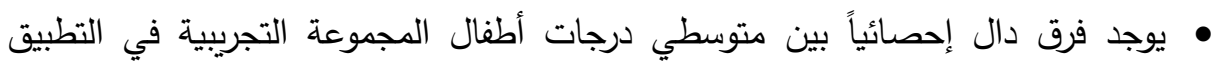
القبلي والبعدي في مقياس السلوك البيئي ككل لصالح التطبيق البعدي.

\section{همبنم المهنه}

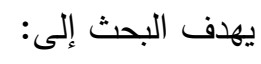

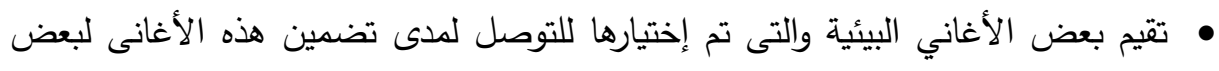

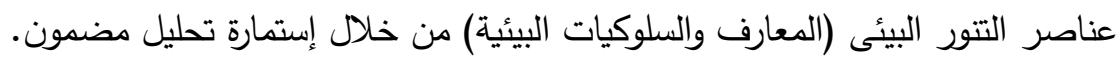
• تنمية التتور البيئي لاى الأطفال من خلال عرض مجموعة من الأفانى البيئية لأطفال الصف الثانى الإبتدائى. - الصن.

\section{أمهبd}

$$
\text { ترجع أهمية البحث الحالي إلى: }
$$

- إعداد إستماره تحليل المضمون يمكن الإستفاده منها فى مجال بحوث التربيه البيئيه

$$
\text { والإعلام. }
$$

- إعداد مقياس تتور بيئي يمكن الإستفادة منه في مجال بحوث التربية البيئية.

$$
\text { المجلد التاسع والأربعون، العدد السابع، الجزء السادس، يوليو •.r.r. }
$$

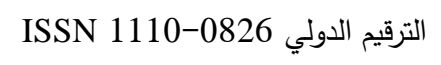




$$
\begin{aligned}
& \text { مجلة العلوم البيئية } \\
& \text { معهد الدراسات والبحوث البيئية - جامعة عين شمس لئ } \\
& \text { رانيا علي محمود وآخرون }
\end{aligned}
$$

- تزويد المؤسسات التعليمية والمكتبة الموسيقية بأغاني الأطفال التي تتضمن القيم والأخلاق والسلوكيات الإيجابية, لكي يتكامل دور المؤسسات التعليمية مع وسائل الإعلام. أهمية نظرية: يفيد البحث فى :

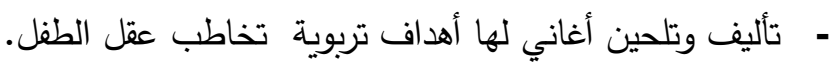
- الإهتمام بالكيف لا بالكم في مضمون أغنية الطفل وإنتقاء الكلمات الهادفة لغرس المبادئ

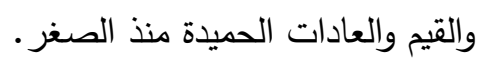
- الإهتمام بتقديم أغاني البيئية موجهة للأطفال قد تساعد على غرس المفاهيم والسلوكيات الإيجابية نحو البيئة.

\section{هصطhاهيت اللهبه}

الأغانى البيئية: بأنها أغنيه ذات مضدون بيئي يتم تأليفها عادةً لأغراض التوعية بالبيئة

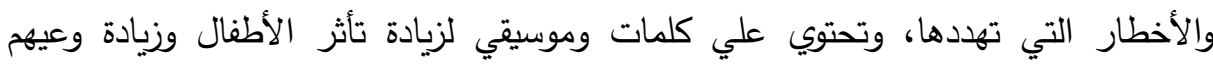
وتعاطفهم مع البيئة المحيطة وما تشتمل عليه من كائنات حية وغير حية.

(Neumann M. M. and Neumann D. L., 2016: p.181) التنور البيئى: عرفه تثين جانج هس بأنه ما يجب إكتسابه من خلال سلوكيات الأفراد بصفة

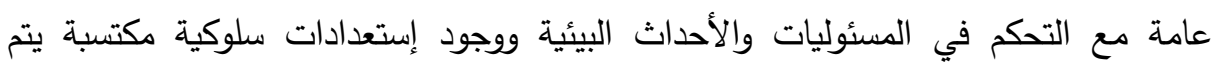
تقديمها من خلال أنشطة وبرامج مُعدة لهؤلاء الأفراد والعمل على تتميتها في المستقبل.

(Shin Jang Hsu, 2004 p. 37-38)

$$
\begin{aligned}
& \text { المجلد التاسع والأربعون، العدد السابع، الجزء السادس، يوليو • . F }
\end{aligned}
$$

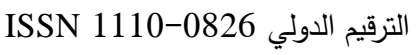




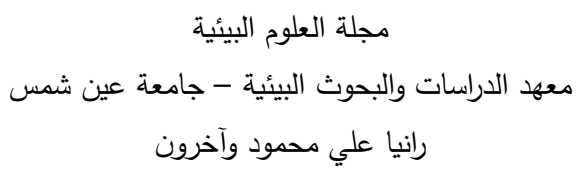

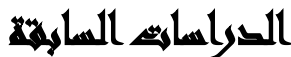

\section{المحور الأول: الدراسات المتعلقة بالأغانى والتربيه البيئيه:}

Miguel Laranjo (2017): Environmental Education through Songs.

هدفت الدراسة إلى التعرف على درجة مساهمة الأغانى فى نشر مبادئ التربية البيئية

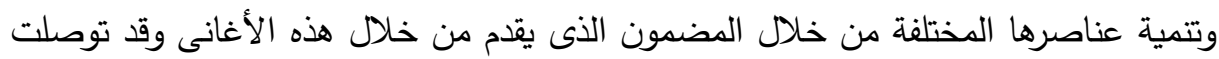

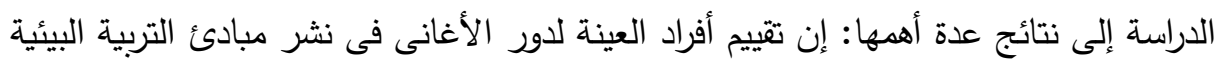

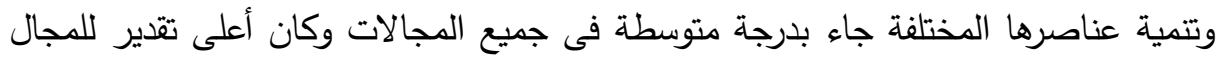

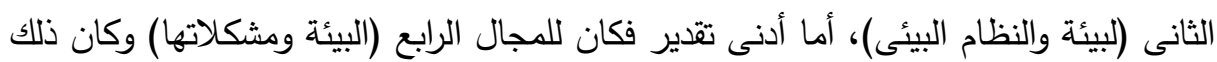
باستخدام استبيان مكون من V \ فقرة موزعة على خمسة مجالات وطبقت على عينة عشوائية

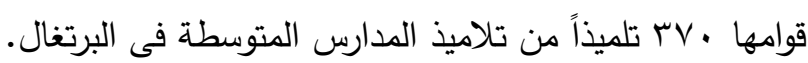

Jennifer Leigh Publicover: Perspectives on songs, the environment, and sustainability education from recording artists featured on the David Suzuki foundation playlist for the planet, 2011, 2016.

دراسة تحليلية توصلت إلى تزايد إستخدام الاغاني على نحو متزايد كأدوات في جداول

أعمال التغيير الإجتماعى، وقد تم الترويج للأغاني بإعتبارها عنصرا حاسما لتحقيق المستقبل

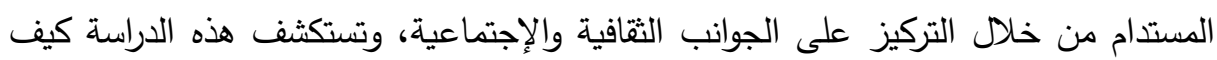
يمكن إستخدام الإغاني لتثجيع السلوك البيئي بإستخدام تقنية أخذ العينات غير الإحتمالية

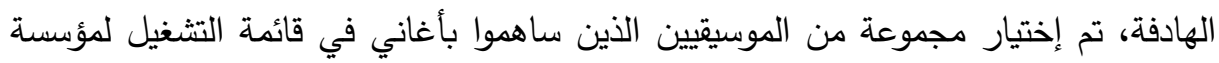

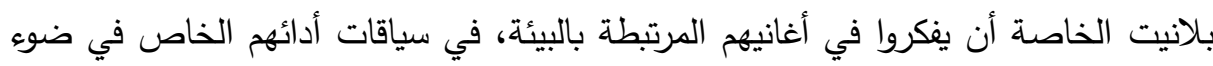

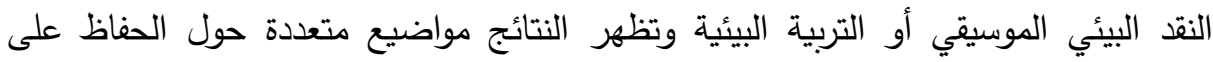
الأصالة الموسيقية في كل من الإخراج الفني والسلوك المؤيد للبيئة، وموازنة الرسائل البيئية

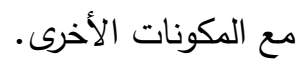

$$
\begin{aligned}
& \text { المجلد التاسع والأربعون، العدد السابع، الجزء السادس، يوليو . F. }
\end{aligned}
$$

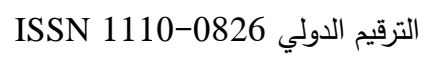




$$
\begin{aligned}
& \text { مجلة العلوم البيئية } \\
& \text { معهد الدراسات والبحوث البيئية - جامعة عين شمس لبنه } \\
& \text { رانيا علي محمود وآخرون }
\end{aligned}
$$

John P. Carroll (2015): The effects of Songs-based environmental education program on children's environmental perceptions"

تقيم هذه الدراسة فاعلية إستخدام الأنثطة الفنية وتقييم الأغاني في برامج صيفية لمدة

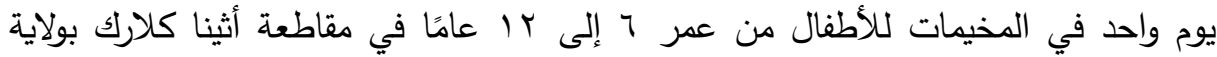

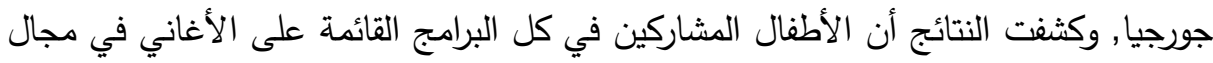

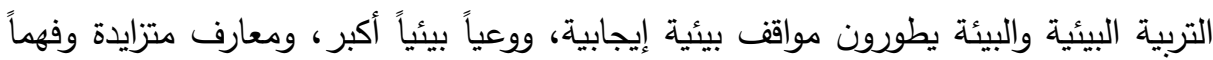
للطبيعة، ومن الأرجح أن يشاركوا في أنشطة الإثراف.

\section{المحور الثانى: الدراسات المتعلقة بالأغانى و التنور البيئى:}

ELNORA LARDER (2018): Environmental Song For The Planet: Educator Perceptions Of An Environmental School Song Program For Environmental Literacy.

هدفت الدراسة إلى فحص أثر برنامج مدرسي للأغاني البيئية على إستجابة الطلاب للتعليم والتتور البيئي من وجهة نظر المعلمين. استخدمت الدراسة منهج دراسة الحالة النوعية. توصلت التحليلات إلى فاعلية الأغاني البيئية في تزويد الطلاب وأسرهم بخبرات بيئية

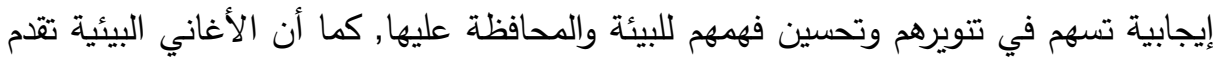

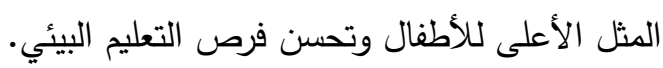

Becky Boudreaux (2016): Environmental Enlightenment Through Songs: The Effectiveness of Environmental Songs in Environmental Awareness Cultivation for Young Children.

هدفت إلى تعرف مستوي التتور البيئي لدي الأطفال وحتى عمر ثمانية سنوات في

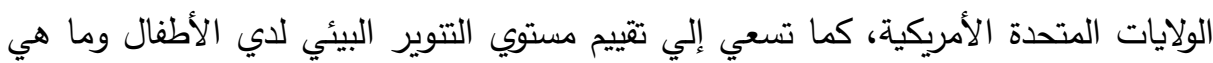
أفضل المناهج المستخدمة لغرس ثقافة وعي وإدراك الأمور البيئية المحيطة، وذلك من خلال التحليل السيميائي للصور والنصوص والفيديوهات المتعلقة بالبيئة, و توصل تحليل الأغانى

$$
\begin{aligned}
& \text { المجلد التاسع والأربعون، العدد السابع، الجزء السادس، يوليو • . F } \\
& \text { الترقيم الدولي 0826-110 110 }
\end{aligned}
$$


إلى سيطرة الأغاني البيئية والموجهة الي الأطفال علي باقي الفئات العمرية, أما المواضيع

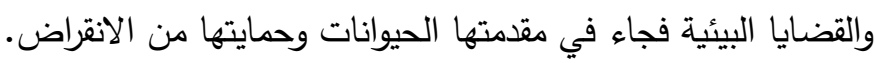
Jessica Vandrick (2015): Impact of Songs on Satellite Channels on Awareness and Environmental Enlightenment for Kindergarten Children.

هدفت الدراسة إلي التعرف على درجة تأثير الأغاني البيئية على مستوى التتوير البيئي

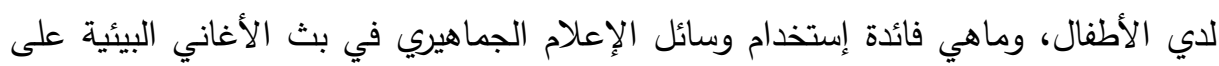
مستوي الوعي البيئي لدي الأطفال، وكيف يتم إستخدام الأغاني بفعالية لإعلام الأطفال

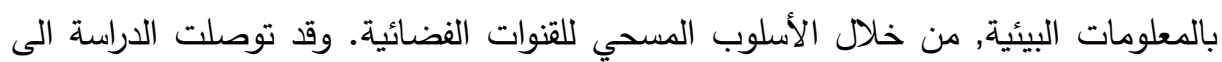

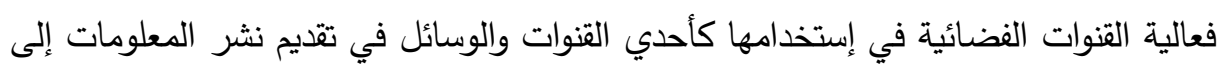

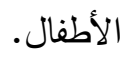

\section{المحور الثالث:الدراسات المتعلقه بالتنور البيئى:}

دراسة رانيا الدمرداش محمد السيد (9 ( ب): بعنوان فاعلية إستخدام التعبير الفنى لتتميه

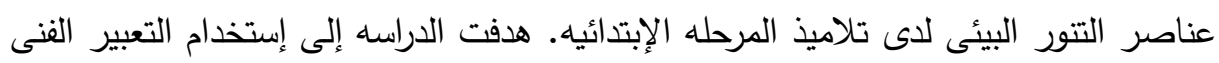

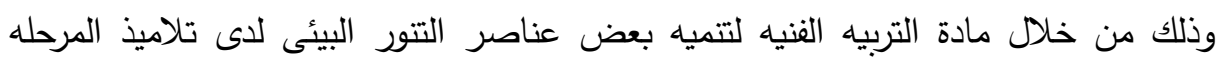
الإبتدائيه حيث قامت الباحثه بتطبيق إختبار تحصيلي للمعارف البيئيه ومقياسا للأتجاهات البيئيه ومقياسا لمهارة حل المشكلات البيئيه على عينه قوامها (.0) تم تقسيمهم لمجموعتين

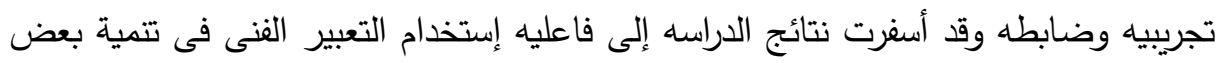
عناصر التتور البيئي لاى تلاميذ الصف السادس الإبتدائى ككل وفى أبعاده الفرعيه (المعارف البيئيه-الأتجاهات البيئيه-مهارة حل المشكلات).

دراسة أمل سعيد عبد الحميد إبراهيم (9 (19): بعنوان برنامج مقترح للتتور البيئي للأطفال

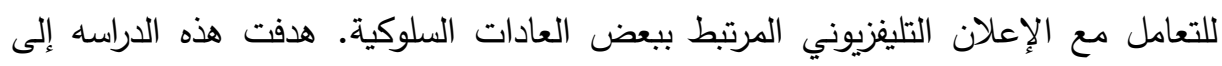
تتمية التتور البيئى للاطفال للحد من العادات السلوكية غير السليمة من خلال عمل برنامج

$$
\begin{aligned}
& \text { المجلد التاسع والأربعون، العدد السابع، الجزء السادس، يوليو . r. }
\end{aligned}
$$

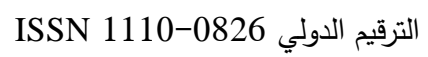


مقترح للتتور البيئى من إعلانات التليفزيون المختلفة،ولتحقيق هذا الهدف قامت الباحثة بتطبيق مقياس التتور البيئي للأطفال للتعامل مع الإعلان التليفزيوني المرتبط ببعض التئي العادات

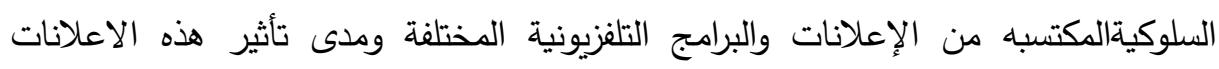
والبرامج عليهج. توصلت الدراسة إلى مجموعة من النتائج ومنها: وجود فروق ذات الترات دلالة

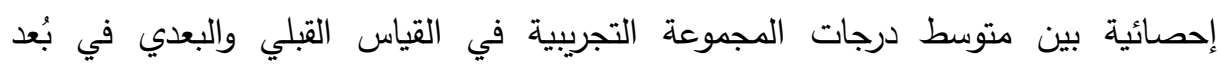
السلوكيات المكتسبة من الإعلان التليفزيوني لصالح القياس البعدي.

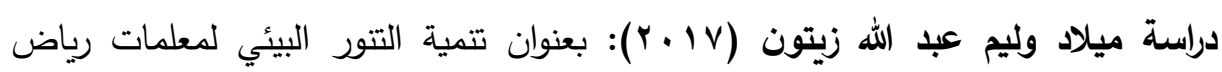

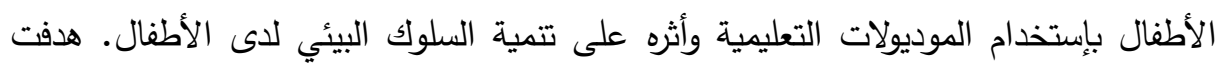

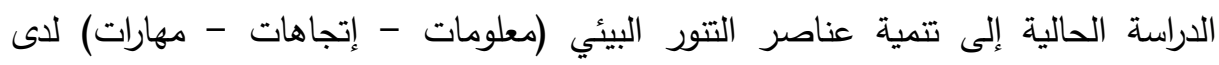
معلمات رياض الأطفال بإستخدام الموديولات التعليمية، وقياس أثر ذلك على سلوك أطفالهن

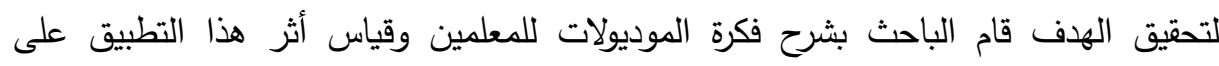
الأطفال من خلال مقياس التتور البيئى عليهم. وتوصلت الدراسة على فاعلية المديولات التعليمية فى تتمية التتور البيئى لاى الأطفال.

\section{الإطالار المعرهنى اللهمبه}

المحور الأول: الأغانى: لقد تتوعت مجالات الأغانى وظهر منها ما يهتم بالبيئة واطلق عليه

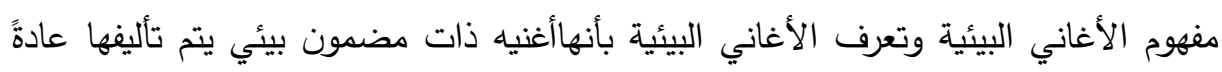

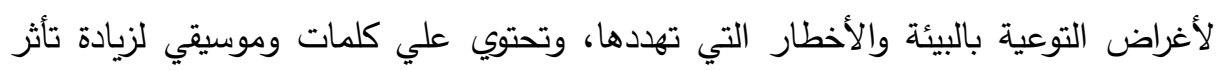

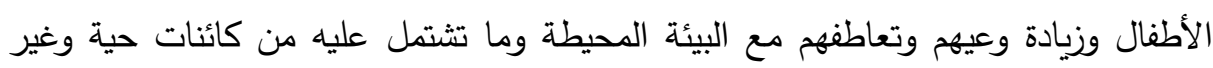

حية. الو (Neumann M.M. and Neumann D.L., 2016) تعرف أيضا بأنها المواد التي يتم استخدامها من ضمن وسائل التعليم البيئي لزيادة

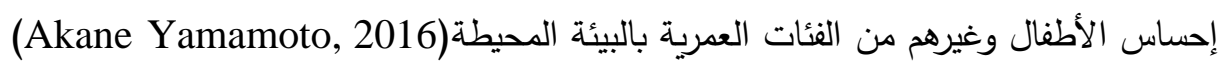
188

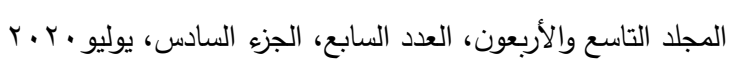

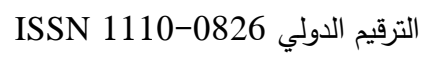


كذلك هى تلك الأغاني ذات الكلمات المساندة للبيئة, وتتكون من ثلاثة مراحل رئيسية هي: مرحلة اختيار الأغنية واختيار الموضوع ومحتوى وكلمات الأغنية, ثم اختيار الألحان المألوفة للتلاميذ, ثم ممارسة النشاط الغنائي, ثم تسجيل استجابات التلاميذ واستيعابهم للأغنية البيئية,

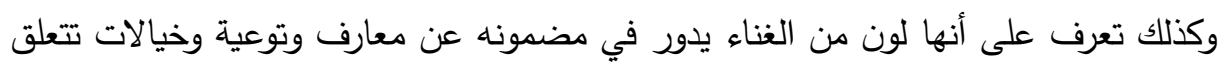

بالبيئية والمحافظة عليها. (Silvers, Michael Benjamin, 2015) فالأغاني البيئية لها تأثير علي التتور البيئي للأطفال, فتؤكد الكثير من الدراسات التي

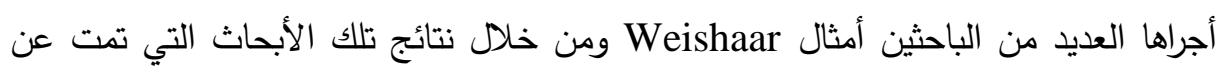
طريق الملاحظة او من خلال المقابلات مع الاطفال أو حتي أولياء امورهم، أن الأغاني لئي

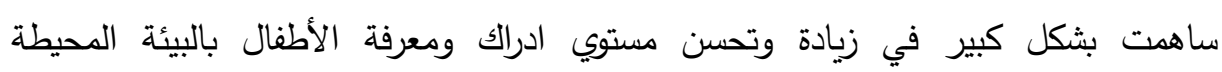
وبالمشاكل التي تعاني منها البيئة وما يجب القيام به للدحافظة علي تلك البيئة، وتثير نتائج

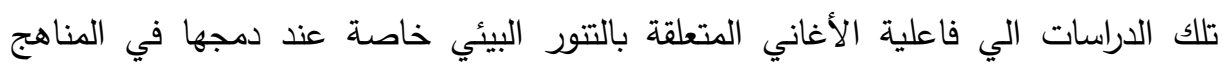

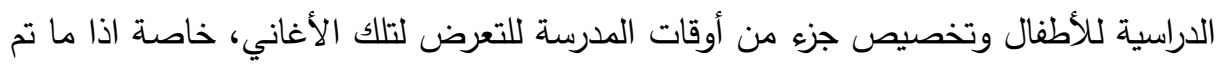
تفعيل ودمج الفيديوهات والرسوم المتحركة والتي يكون لها بالغ التأثير علي وعي وادراك الأطفال للبيئة. (Murphey, Tim, 2010) وتتنوع الموضوعات والقضايا التي تعالجها الأغاني البيئية, حيث تسعي الأغاني البيئية الي مناقشة العديد من الموضوعات ومنها المحافظة على الماء والهواء وعدم تلويثهما,

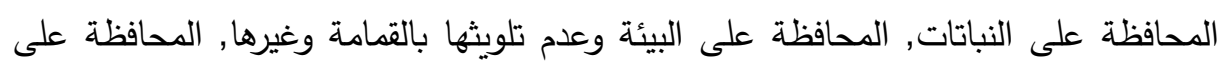
الحيوانات خاصة تلك المعرضة للإنقراض. (Becky Boudreaux, 2016) المحور الثانى: التنور البيئى: يمكن تصنيف محاولات إعطاء معنى للتنور البيئى وفق ثلاث 
الصورة الأولى: تقديم تعريف محدد لمفهوم التتور البيئى، إذ عُرف التتور البيئى على أنه

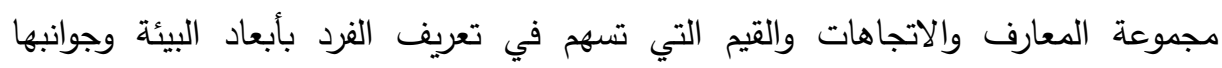
وحدودها من حوله، والسبل المناسبة للحفاظ على سلامتها وعدم تلوثها. (Hsu, S.J., 2004)

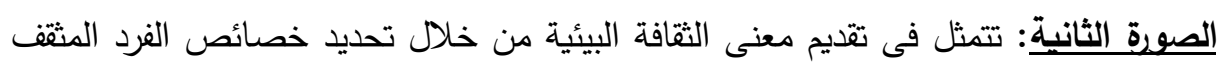
بيئياً وسماته، وقد حددت خصائص الفرد المتتور بيئياً بأنه يمتلك المعرفة البيئية المناسبة،

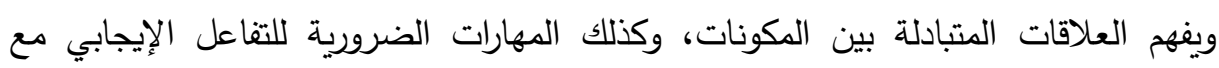
البيئة، ولديه الاتجاهات والقيم اللازمة للممارسة البيئية، ويتخذ قرارات تتلاعم مع نوعية الحياة ونوعية البيئة. الصورة الثالثة: فقدمت مفهوم التتور البيئى من خلال تحديد أبعاده أو مكوناته مابين معرفى ووجدانى ومهارى وسلوكى. (Roth, 1992) وتعددت أبعاد عناصر التنور البيئى، ومنها: المعارف البيئية: تعرف بأنها المعلومات الأساسية المرتبطة بالبيئة ومكوناتها، والتي تزود الفئئ الفرد

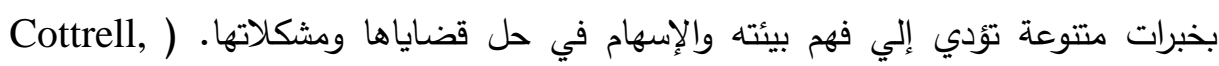

السلوك البيئي: يشير مفهوم السلوك البيئي إلى كل ما يصدر من الفرد من أفعال وتصرفات

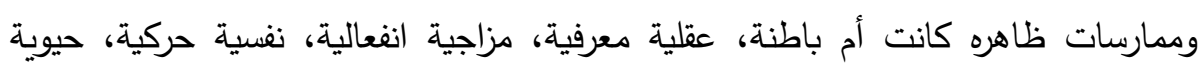

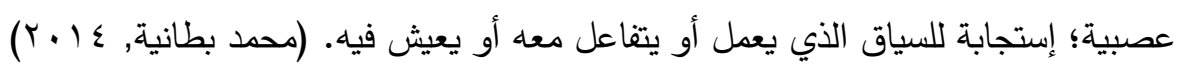

\section{إجبراعاهي الهمبث}

$$
\text { منهج البحث: يستخدم البحث الحالى: }
$$

المنهج الوصفي: وذلك بتحليل مضمون مجموعة من أغاني الموجهة للأطفال والتى تتضمن

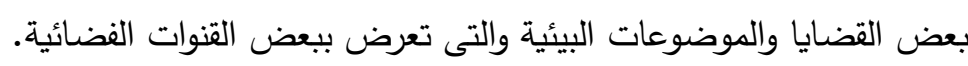
190

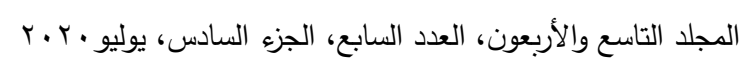

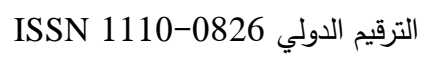


المنهج شبه التجريبي: من خلال تعريض الأطفال للأغاني للتعرف على أثر المتغير المستقل

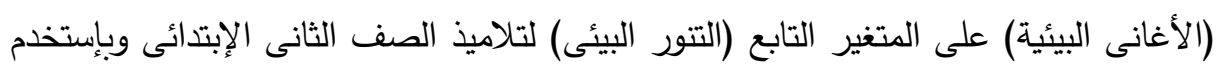

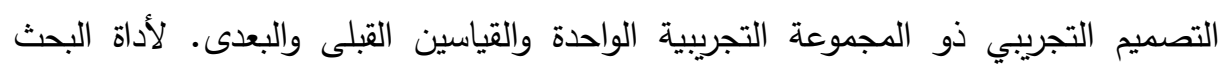
المتمثله في مقياس التتور البيئي.

أدوات البحث: أولاً: إعداد قائمة بعناصر التنور البيئي: تم إعداد الصورة الأولية للقائمة وعرضها على السادة المحكين لإبداء الرأى وتوصل الباحثون للثكل النهائى للقائمة (0) قضايا رئيسة تتضمن مجموعة من السلوكيات والمعارف المرتبطة بها، كما يوضحه الجدول

جدول (Y): قائمة عناصر التتور البيئى

\begin{tabular}{|c|c|c|c|c|}
\hline \multicolumn{2}{|c|}{ السلوكيات البيئية المرتبطة بالقضية } & \multicolumn{2}{|c|}{ المعارف البيئية المرتبطة بالقضية } & \multirow{2}{*}{ البيئية } \\
\hline السلبي & الإيجابي & المعلومات المرتبط & المفاهيم المرتبط & \\
\hline \multirow{6}{*}{ 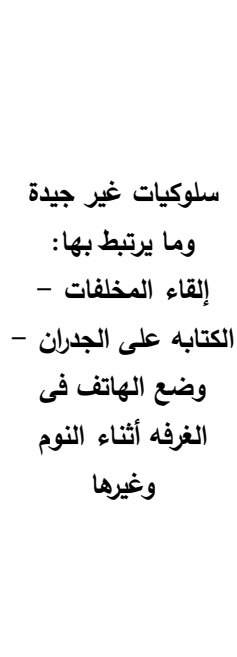 } & \multirow{6}{*}{ بالتعامل الجيد مع هذهات الإيجابية المرتبطة العناصر : } & أسباب - مظاهر - & تلوث الهواء & \multirow{6}{*}{ 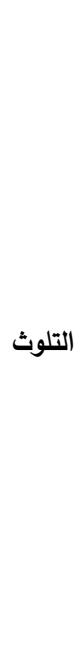 } \\
\hline & & أسباب - مظاهر - & تلوث الماء & \\
\hline & & أسباب - مظاهر - & التلوث السمعي & \\
\hline & & أسباب - مظاهر - & تلوث التربة & \\
\hline & & أسباب - مظاهر - & التلوث البصري & \\
\hline & & أسباب - مظاهر - & الكهرومغناطيسي التلوث & \\
\hline
\end{tabular}

$$
\text { المجلد التاسع والأربعون، العدد السابع، الجزء السادس، يوليو • ·. r. }
$$




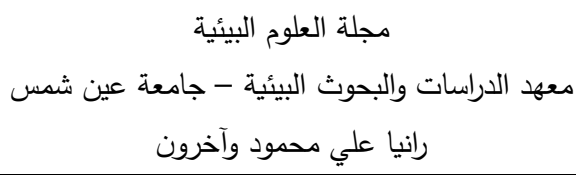

\begin{tabular}{|c|c|c|c|c|}
\hline \multicolumn{2}{|c|}{ السلوكيات البيئية المرتبطة بالقضية } & \multicolumn{2}{|c|}{ المعارف البيئية المرتبطة بالقضية } & \multirow{2}{*}{ البيية } \\
\hline السلبي & الإيجابي & المعلومات المرتبط & المفاهيم المرتبط & \\
\hline سلوكيات اهدار الماء & سلوكيات استخدام الماء وما & ترشيد الاستهلاك ومقترحات & ترشيد استهلاك & \multirow{3}{*}{ الاستهلاك } \\
\hline الكهرباء وما يرتبط بهات اهدار & سلوكيات استخدام الكهرباء وما & ترشاهر ومقترحات & ترشيد استهلاك & \\
\hline سلوكيات اهدار الغذاء & سلوكيات استهلاك الغذاء وما & ترشيد الاستهلاك ومقترحات & ترشيد الاستهلاك & \\
\hline \multirow{3}{*}{$\begin{array}{c}\text { الألقاء المخلفات على - الكتابة على } 1 \text { الجدران } \\
\text { الجلى }\end{array}$} & \multirow{3}{*}{ الاشتراك مع الزملاء فلى نظافة النظافة الفصل - الملة } & مظاهر - مقترحات & نظافة المدرسة & \multirow{3}{*}{ النظافة } \\
\hline & & مظاهر - مقترحات & نظافة الحديقة & \\
\hline & & مظاهر - مقترحات & نظافة الشارع & \\
\hline صنداء المخلفات خارج & إلقاء المخلفات فى المكان & أسباب - مظاهر - & 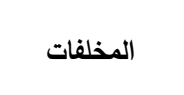 & 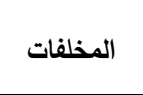 \\
\hline \multirow[b]{2}{*}{ افساد المظهر الجمالى } & \multirow[b]{2}{*}{ الحفاظ على المظهر الجمالى } & \multirow[b]{2}{*}{ مظاهر - مقترحات } & البيئه & \multirow{2}{*}{ حاية البيئة } \\
\hline & & & المستدامة & \\
\hline المستهلكات دون الاستفادة منها & استخدام المستهلكات فى عمل أشياء مفيدة & مظاهر - مقترحات & إعادة الاستخدام & الاستخدام \\
\hline
\end{tabular}

ثانياً: تصميم إستمارة تحليل مضمون: قام الباحثون بتصميم إستمارة تحليل المضمون وعرضها على مجموعه من الساده المحكين لوضعها فى صورتها النهائيه وتوصل الباحثون للشكل النهائى لإستمارة تحليل المضمون حيث تم تحديد فئات التحليل والتى اشتملت على:

$$
\begin{aligned}
& \text { 1- فئات الثكل (كيف قيل؟) وتتضمنت الآتى: } \\
& \text { / 1/ اسم الأغنية }
\end{aligned}
$$

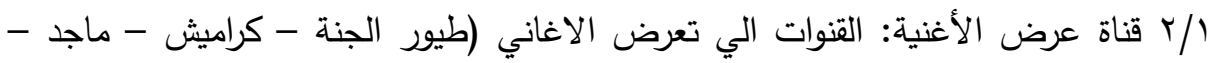

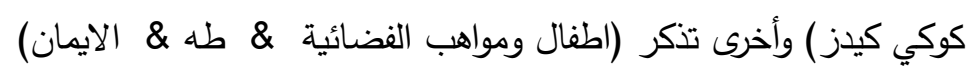

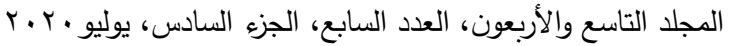

$$
\begin{aligned}
& \text { الترقيم الدولي 1SSN 1110-0826 }
\end{aligned}
$$


\&/ Tئة فترة إذاعة الأغنية: أي تحديد اذا إذيعت الأغنية في الفترة الصباحية او فترة الظهيرة \& فترة المساء \& فترة السهرة

/ / فئة المساحة الزمنية للأغنية: ويقصد بهاء الوقت المخصص لإذاعة الأغنية والمدة الزمنية التي إستغرقتها على الثاشة.

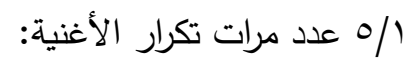

وتهدف هذه الفئة إلى معرفة عدد مرات إذاعة الأغاني سواء كانت مرة واحده أو مرتين أو ثلاث مرات أو اكثر من ثلاث مرات. // آ فئة اللغة المستخدمة في الأغنية: وتهدف إلى معرفة اللغة التي إذيعت بها الأغنية سواء كانت العربية والتي شملت (فصحى فصحى مبسطة) أو العامية.

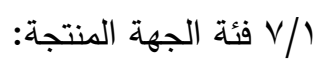
وتهدف هذه الفئة للتعرف على الجهة التي أنتجت الأغنية سواء كانت جهة محلية (حكومي, خاص) أو جهة عربيه. 1/ 1/ فئة المكان الذي تم تصوير الأغنية فيه: وتهدف هذه الفئة للتعرف على المكان الذي تم فيه تصوير الأغنية فيه سواء كان داخل إستوديو وشملت (شقة - مسرح - جرافيك) أو خارج الإستديو والتي شملت (شارع - حديقة ملاهي).

/ / فئة مدى وجود ع عوامل جذب مقدمه في تصوير الأغنية:

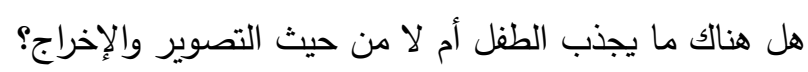

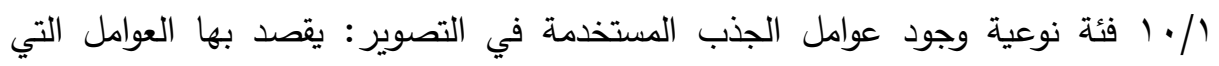
إستعان بها مخرج الأغنية لكي يجذب الطفل سواء كانت (رقص المؤديين للأغنية \& ترديد

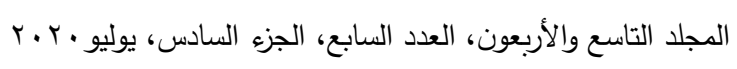

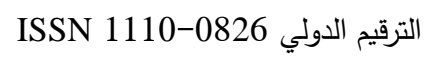


الاطفال لكلمات الأغنية \& الالوان \& المؤثرات السمعية والبصرية \& استخدام عرائس او شخصية كارتونية \& تقمص الأطفال الأدوار المختلفة \& تمثيل الأطفال).

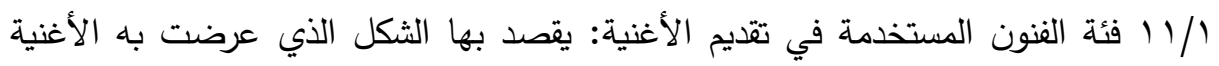
سواء كان رسوما متحركة او عرض مسرحي \& أوبربت غنائي \& عرائس \& ع أطفال.

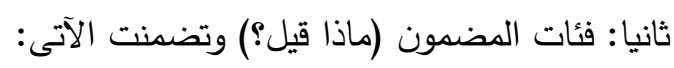

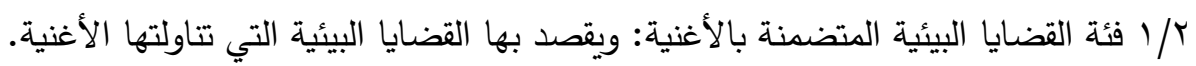
التلوث ويشمل: (تلوث الهواء - الماء - السمعي - التربة - البصري - الكهرومغناطيسي) ترشيد الإستهلاك ويشمل: (ترشيد إستهلاك الماء - الطاقة - الغذاء) النظافة وتثمل: (نظافة الحديقة - المدرسة - الثارع) المخلفات

حماية البيئة والتتمية المستدامة

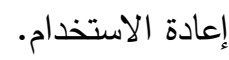
r/T فئة المعارف البيئية المتضمنة بالأغنية: يقصد بها المفاهيم والمعلومات التي تضمنها الأغنية بالنسبة لكل قضيه من القضايا من حيث (المفهوم - المظاهر - الأسباب -

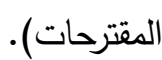
r/ Tئة السلوكيات البيئية المتضمنة في الأغنية: يقصد بها السلوكيات البيئية التي تضمنها الأغنية سواء كانت إيجابية أو سلبية بالنسبة لكل قضيه من القضايا.

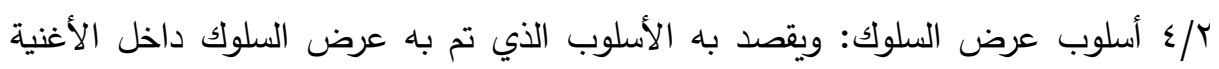

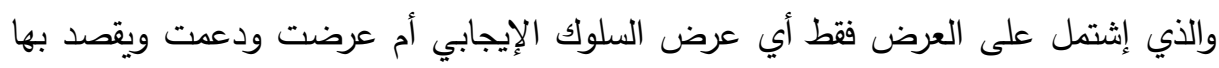
عرض السلوك السلبي وتدعيمه بالسلوك الإيجابي.

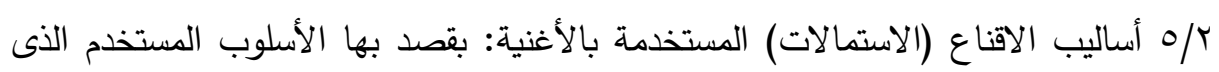
تعرض به القضية والإقناع بها و تثمل: 194

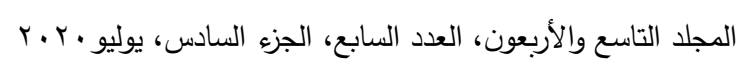

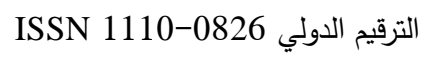


إستمالات عاطفية: تخاطب قلب ووجدان الطفل سواء كانت عن طريق إسلوب الترغيب عن طريق تحبيب الطفل وإستثارة مشاعر الإنتماء في حب البيئة وأهمية الإحساس بمسئولية الفرد تجاه بيئته والمشاركة الإجتماعية للقيام بسلوك إيجابي وتحفيزه للحفاظ على البيئة. او بأسلوب الترهيب عن طريق عرض نوعا من العقاب المعنوي للطفل لتنفيره من القيام بسلوكيات سلبيه تجاه البيئة. إستمالات منطقيه: أي التي تخاطب العقل بالاستشهاد بواقع الأحداث وعرض أسباب تقنع الطفل بالإلتزام بالأفعال الايجابية للحفاظ على البيئة. أو بالإثثين معا: ويقصد بها إستخدام الإستمالات العاطفية والمنطقيه معاً.

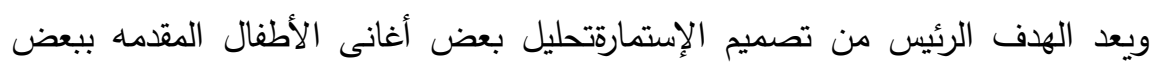

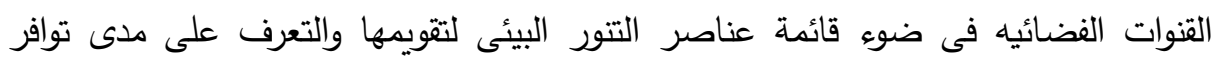
عناصر التتور البيئى محل أهتمام الدراسه المتمثلة في المعارف والسلوكيات البيئية. حيث تم حصر مجموعه من الأغانى التى تتناول بعض القضايا والموضوعات المرتبطه

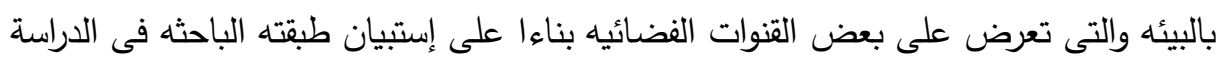

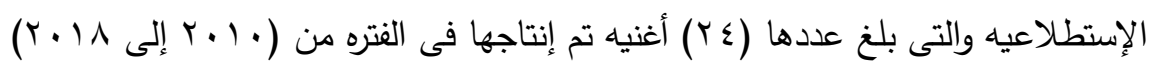
جدول (r):

\begin{tabular}{|c|c|c|c|}
\hline القضايا المتضمنة & سنة الإنتاج & اسم الأغنية & م \\
\hline \multicolumn{4}{|c|}{ قناة طيور الجنة: } \\
\hline - - حماية البيئة والتتمية الكستداملاءة) & $r .1$. & طاقة طاقة طاقية والطاقة مسئولية & 1 \\
\hline - ترشيد الاستهلالك (الماء). & $r+1 r$ & لا تسرف في الماء & $r$ \\
\hline - ترشيد الاستهلالك (ماء - كهرباء - غذاء) & $r .10$ & ما أحلى التوفير & $r$ \\
\hline - التلوث البصري. & $r .1 Y$ & شخابيط & $\varepsilon$ \\
\hline - حماية البيئة والتنمية المستدامة. & $r \cdot 1 \Lambda$ & 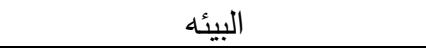 & 0 \\
\hline - تلوث (هواء - ماء - مائة - تربة - سمعىى). & $r .1$. & 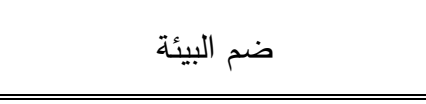 & 7 \\
\hline
\end{tabular}




\begin{tabular}{|c|c|c|c|}
\hline \multicolumn{4}{|c|}{ 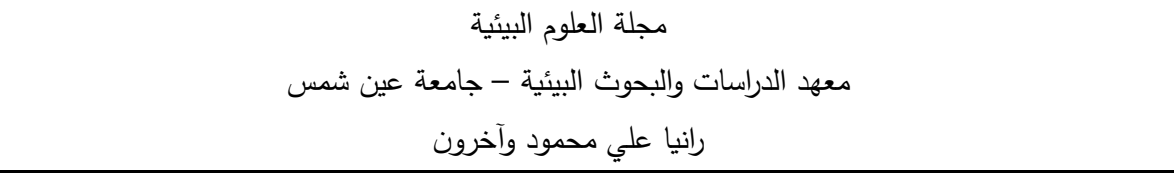 } \\
\hline \multicolumn{4}{|c|}{ تابع جدول (r): } \\
\hline \multicolumn{4}{|c|}{ قناة كراميش: } \\
\hline - ترشيد إستهلاك (الماء). & $r \cdot 1 r$ & 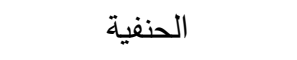 & 1 \\
\hline - - حماية البيئة والتمية المستدامة. & $r \cdot 1 \leq$ & أحمي البيئة & $r$ \\
\hline - ترشيد الإستهلاك (الكهرباء). & $r \cdot 10$ & 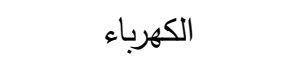 & r \\
\hline - التلوث السمعي. & $r \cdot 11$ & إزعاج & $\varepsilon$ \\
\hline - - حماية البيئة والتتمية المستدامة. & $r .1 r$ & خلي كياسك على قياسك & 0 \\
\hline \multicolumn{4}{|c|}{ قناة ماجد: } \\
\hline - - ترشيد الإستهلالك (ماء - كهرباء). & $r .17$ & هيا نبدأ بالترشيد & \\
\hline \multicolumn{4}{|c|}{ قناة كوكي كيدز: } \\
\hline - - حماية البيئة والتتمية المستدامة. & $r .17$ & أنا البيئة أحبائى & 1 \\
\hline - ترشيد الإستهلاك (ماء). & $r .11$ & 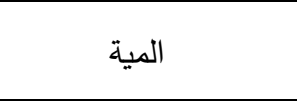 & r \\
\hline - النظافة (المدرسة). & $r \cdot 17$ & 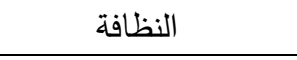 & r \\
\hline - حماية البيئة والتتمية المستدامة. & $r \cdot 11$ & 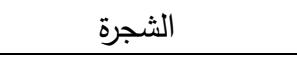 & $\varepsilon$ \\
\hline - التلوث البصري. & $r \cdot 1 r$ & شخبط شخابيط & $\circ$ \\
\hline \multicolumn{4}{|c|}{ قناة طه: } \\
\hline - ترشيد الإستهلاك (كهرباء). & $r .17$ & أضواء & 1 \\
\hline - - - حماية البيئة والتتمية المستداءك) (ماء). & $r \cdot 1 \leq$ & تعطل الصنبور & $r$ \\
\hline - - التلوث السمعي. & $r \cdot 11$ & يا عمو خفف تزمير & r \\
\hline
\end{tabular}

196

$$
\begin{aligned}
& \text { المجلد التاسع والأربعون، العدد السابع، الجزء الساد، يوليو • r. }
\end{aligned}
$$

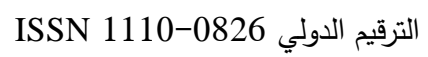




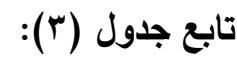

\begin{tabular}{|c|c|c|c|}
\hline \multicolumn{4}{|c|}{ قناة الإيمان: } \\
\hline - - حماية البيئة والتتمية المستدامة. & r.lı & أزرع لا تقطع & 1 \\
\hline - - حماية البيئة والتتمية المستدامة. & $r .1 \leq$ & الحفاظ على البيئة & $r$ \\
\hline \multicolumn{4}{|c|}{ قناة أطفال ومواهب: } \\
\hline - - حماية البيئة والتتمية النستدامة.الثارع. & $r .1 r$ & حافظ على مدينتك & 1 \\
\hline - & $r .11$ & إعمل خير وأرمي للسلة & $r$ \\
\hline
\end{tabular}

ثالثا: إعداد مقياس التنور البيئى: قام الباحثون بالخطوات التالية:

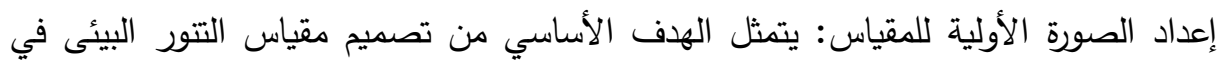

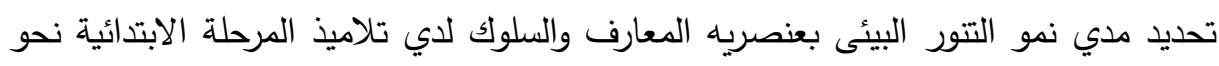

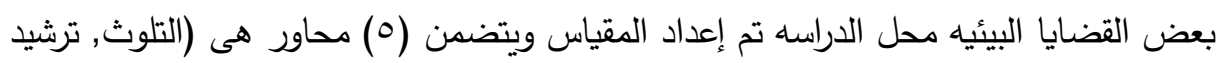
الاستهلاك، النظافة، المخلفات، حماية البيئة والتتمية المستدامة) فى كل مكوناته وتم عرضياته

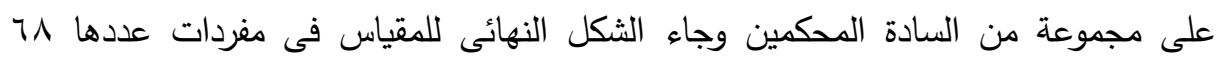
مفردة (•r مفردة خاصة بإختبار المعارف) و(^r مفردة خاصة بمقياس السلوك البيئى)

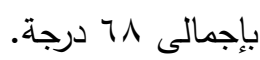

الأول: إختبار المعارف البيئية: يهدف إلى التعرف علي المفاهيم والمعلومات المرتبطة بكل

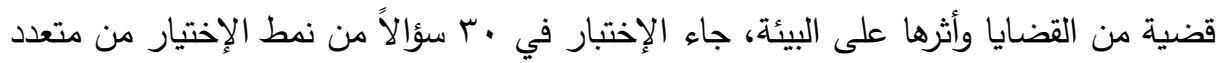

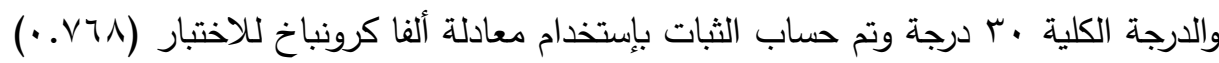
أن الاختبار يتمتع بمعامل ثبات مرتفعة ومقبولة..

الثانى: مقياس السلوك البيئى: هدف المقياس إلى تحديد مستوى السلوك البيئى لدى التلاميذ،

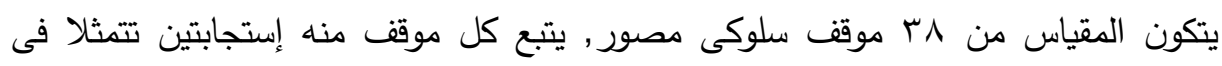

$$
\begin{aligned}
& \text { المجلد التاسع والأربعون، العدد السابع، الجزء الساد، يوليو • r. }
\end{aligned}
$$

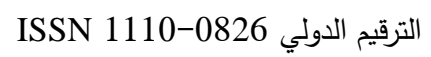


سلوك صحيح وسلوك غير صحيح وجاءت درجته الكلية بـ درجة، وجاء حساب ثبات المقياس (9VT, · · ) أن مقياس السلوك البيئى يتمتع بمعامل ثبات مرتفعة ومقبولة.

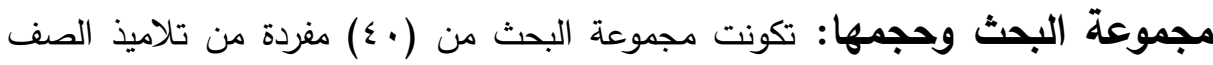
الثانى الإبتدائى، ع ب تلميذ و 17 تلميذه. فترة ونطاق التطبيق الميداني: تم التطبيق لمدة 10 يوماً متتالية فى الفترة

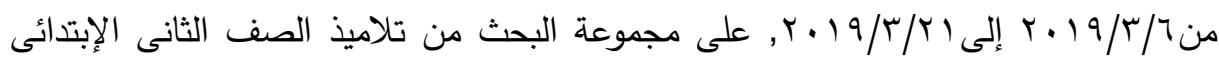

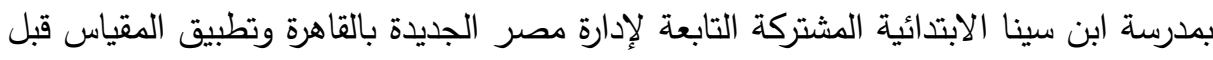
وبعد عرض الأغانى على التلاميذ.

\section{ندائز اللهميث}

نتائج الدراسه التحليليه: جدول (؛): المعارف والسلوكيات المستخدمة في القضايا البيئية التى تضمنتها الأغانى "عينة الدراسة"

\begin{tabular}{|c|c|c|c|c|c|c|}
\hline \multicolumn{2}{|c|}{ الاجمالي } & \multicolumn{2}{|c|}{ 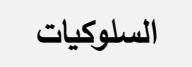 } & \multicolumn{2}{|c|}{ المعارف } & مال \\
\hline$\%$ & S & $\%$ & s & $\%$ & ك & \\
\hline$r v, T$ & or & $r 7,9$ & $T \leqslant$ & $r \wedge, r$ & rq & التلوث \\
\hline$r q, r$ & 07 & $M, \varepsilon$ & rA & $r V, r$ & rA & ترشيد الاستهلالك \\
\hline $\mathrm{V}, \Lambda$ & 10 & $0, V$ & 0 & $9, v$ & 1. & 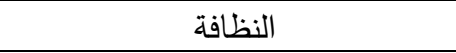 \\
\hline $0, Y$ & 1. & $r, \varepsilon$ & $r$ & $7, V$ & $\mathrm{~V}$ & المخلفات \\
\hline$r \cdot, r$ & 01 & $M r, T$ & rq & $r \wedge, r$ & rq & حماية البيئة والتتمية المستدامة \\
\hline $1 \ldots$ & 194 & $1 \ldots$ & 19 & $1 \ldots$ & $1 . r$ & المجموع \\
\hline
\end{tabular}

198

$$
\begin{aligned}
& \text { المجلد التاسع والأربعون، العدد السابع، الجزء السادس، يوليو . r. } \\
& \text { الترقيم الدولي 0826-1110 }
\end{aligned}
$$




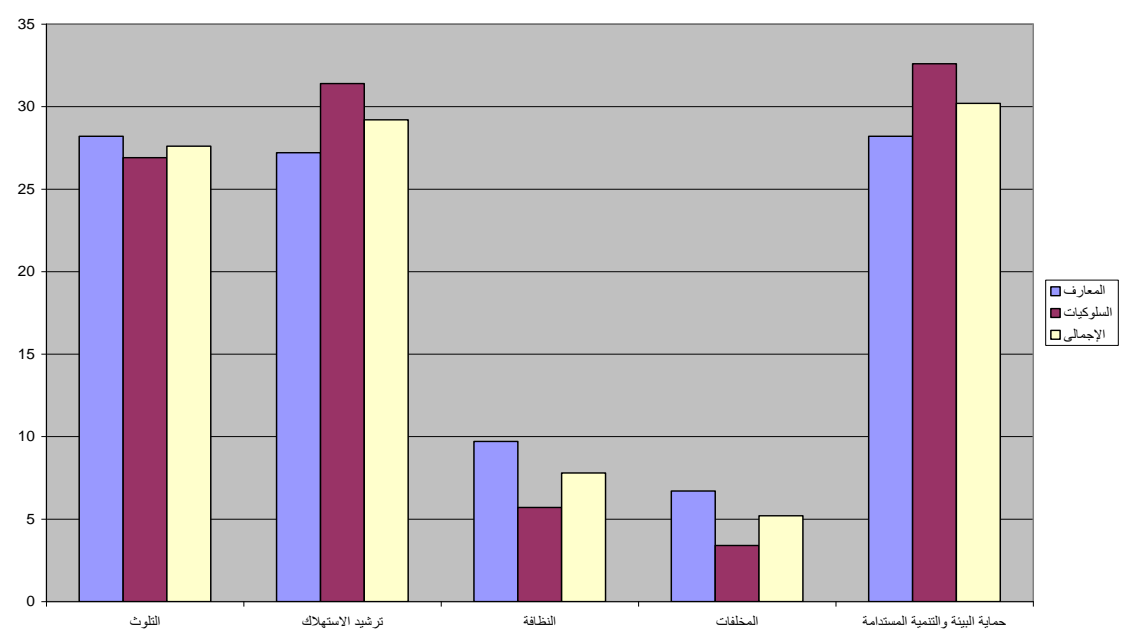

شكل (1): يوضح مقارنة نسبة ظهور المعارف والسلوكيات فى الأغانى البيئية المقدمة بالقنوات محل الدراسة

ويتضح من تحليل بيانات الجدول والثكل السابقين ما يلي: جاءت قضية "حماية البيئة والتتمية المستدامة" فى الترتيب الأول من حيث احتوائها على المعارف والسلوكيات لعرض

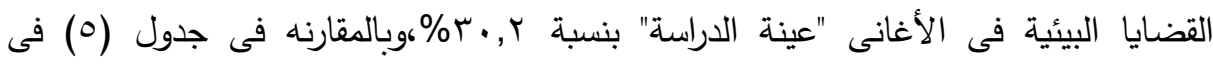

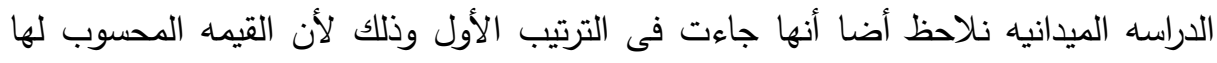

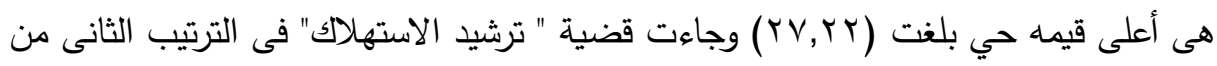

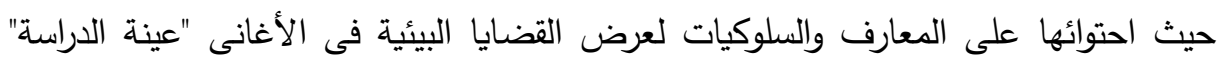

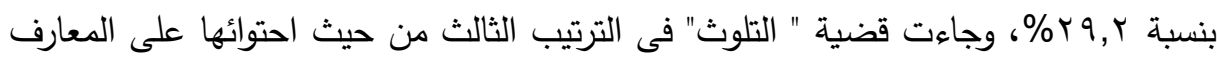

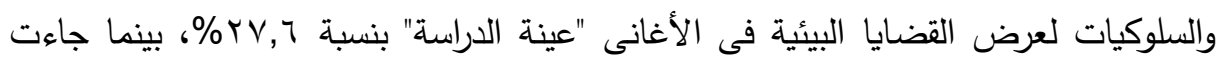

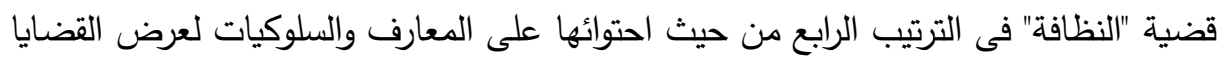

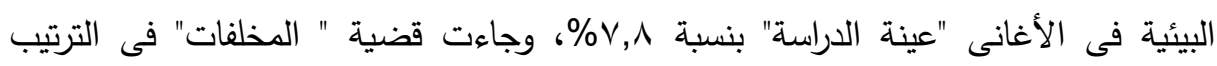


الخامس والأخير من حيث احتوائها على المعارف والسلوكيات لعرض القضايا البيئية فى

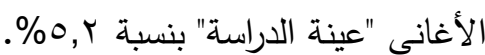

نتائج الدراسه الميدانيه: للتحقق من صحة الفرض الأول: جدول (•): متوسطي درجات اطفال المجموعة التجريبية في القياس القبلي والقياس البعدي

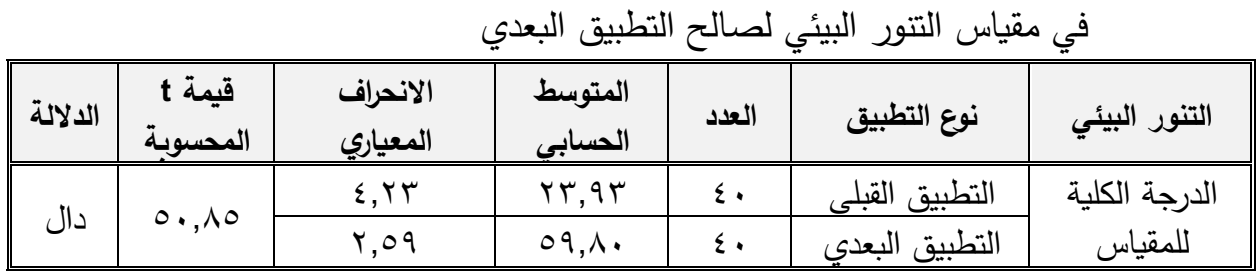

ويتضح من نتائج جدول (0) أن قيمة (ت) المحسوبة البالغة (10, •.0) أكبر من قيمة

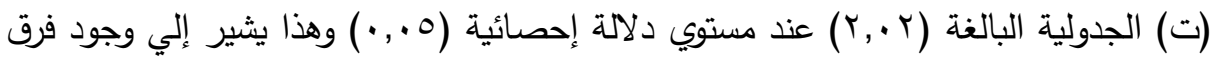

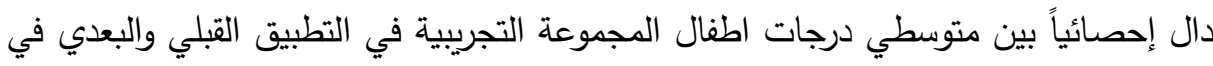
مقياس التتور البيئي ككل لصالح التطبيق البعدي حيث لوحظ ارتفاع متوسط درجات اطفال المجموعة التجريبية في التطبيق البعدي البالغ (•^,هـه عن متوسط درجاتهم في التطبيق القبلي البالغ (r,q.9) أي أن للاغاني البيئية فاعلية في تتمية التتور البيئي ككل والثكل

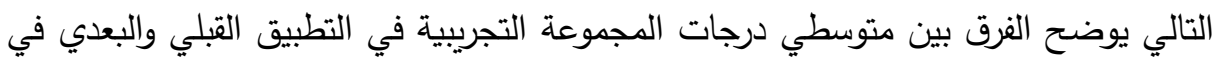

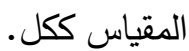

وللتحقق من تأثير استخدام الاغاني البيئية في تتمية ابعاد التتور البيئي ككل لدى اطفال

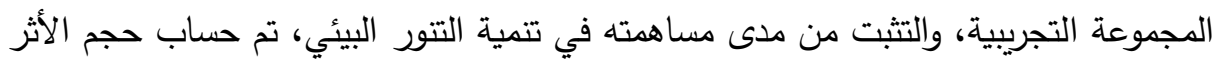

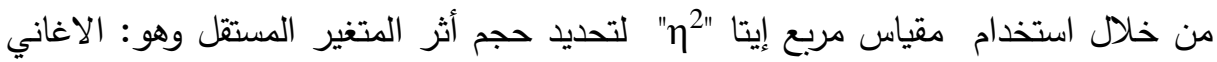
البيئية على المتغير التابع وهو: التتور البيئي. 
جدول (ך): قيم مربع ايتا (ך) وقيمة (d) المقابلة لها ومقدار حجم أثر استخدام الاغاني في تتمية التنور ككل

\begin{tabular}{|c|c|c|c|c|c|}
\hline ملاحظة & قيمة حجم الأثر & قيمة مربع ايتا & درجة الحربة & قيمة (t) & المتغير \\
\hline حجم الاثر كبير & 17,19 & $\cdot, 99$ & rq & $0 ., 10$ & الدرجة الكلية \\
\hline
\end{tabular}

"قيمة حجم الأثر =.人, · فأكثر مؤشر على أن حجم الأثر جاء بدرجة كبيرة

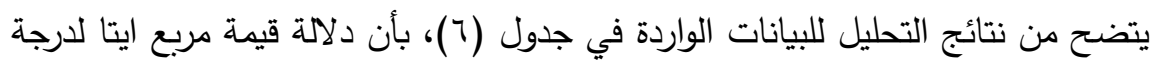

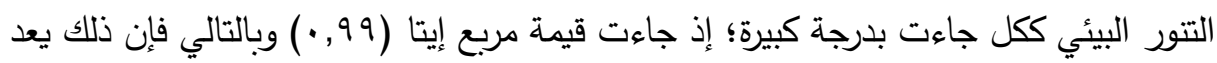
مؤشراً على أن مقدار حجم الأثر (d) جاء بدرجة كبيرة، مما يشير إلى أن استخدام الاغاني البيئي ساهم بدرجة كبيرة في تتمية ابعاد التتور البيئي ككل. للتحقق من صحة الفرض الثانى: جدول (V): يوضح نتائج القياس القبلي والقياس البعدي في المجموعة التجريبية في اختبار

\begin{tabular}{|c|c|c|c|c|c|c|}
\hline & & & & \multicolumn{3}{|c|}{ المعارف البيئية } \\
\hline الدلالة & المحسوبة t قيمة & الانحراف & المتوسط & العدد العد & نوع التطبيق & ابعاد الاختبار \\
\hline \multirow{2}{*}{ دال } & \multirow{2}{*}{ Y),97 } & $1, \leqslant 1$ & $r, Y \wedge$ & $\varepsilon$. & التطبيق القبلي & \multirow{2}{*}{ التلوث } \\
\hline & & $\cdot, 9$. & $\Lambda, 1$. & $\varepsilon$. & التطبيق البعدي & \\
\hline \multirow{2}{*}{ دال } & \multirow{2}{*}{$r Y, \leqslant q$} & 1,11 & 1,90 & $\varepsilon$. & التطبيق القبلى & \multirow{2}{*}{ ترشيد الاستهلاك } \\
\hline & &., 00 & 7,1 . & $\varepsilon$ & التطبيق البعدي & \\
\hline \multirow{2}{*}{ 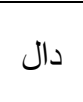 } & \multirow{2}{*}{$1 \leq, 77$} & $\cdot, v_{1}$ & $1, \varepsilon$. & $\varepsilon$. & التطبيق القبلي & \multirow{2}{*}{ النظافة } \\
\hline & & $\cdot, 70$ & $r, v$. & $\varepsilon$. & التطبيق البعدي & \\
\hline \multirow{2}{*}{ دال } & \multirow{2}{*}{$\mid r, \varepsilon \varepsilon$} & $\cdot, 7 \wedge$ & $\cdot, V T$ & $\varepsilon$. & التطبيق القبلى & \multirow{2}{*}{ المخلفات } \\
\hline & &., 00 & $r, \leqslant 0$ & $\varepsilon$. & التطبيق البعدي & \\
\hline \multirow{2}{*}{ دال } & \multirow{2}{*}{$r V, r Y$} & $\cdot, \leqslant 0$ & $\cdot, Y \wedge$ & $\varepsilon$. & التطبيق القبلى & \multirow{2}{*}{ حماية البيئة والتتمية } \\
\hline & & $\cdot, \leqslant\rceil$ & س r, & $\varepsilon$. & التطبيق البعدي & \\
\hline \multirow{2}{*}{ دال } & \multirow{2}{*}{ Tr,v } & $r, 79$ & 7,01 & $\varepsilon$ & التطبيق القبلي & \multirow{2}{*}{ الارجة الكلية } \\
\hline & & $r, I V$ & $r r, \Sigma T$ & $\varepsilon$. & التطبيق البعدي & \\
\hline
\end{tabular}

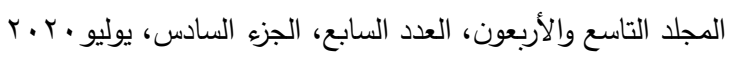

$$
\begin{aligned}
& \text { الترقيم الدولي 0826-0 الانون، }
\end{aligned}
$$




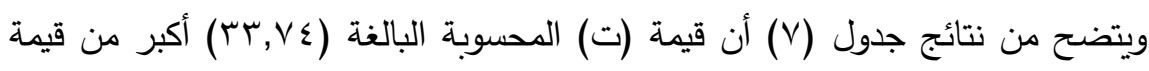

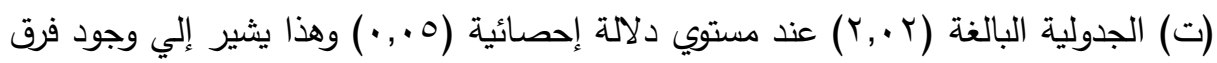

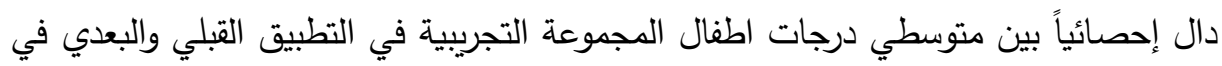
اختبار المعارف البيئية ككل لصالح التطبيق البعدي حيث لوحظ ارتفاع متوسط درجات الطفال

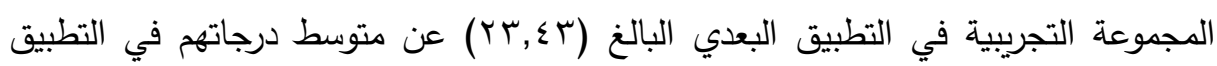
القبلي البالغ (7,01) اي أن للاغاني البيئية فاعلية في تتمية المعارف البيئية ككل والثكل

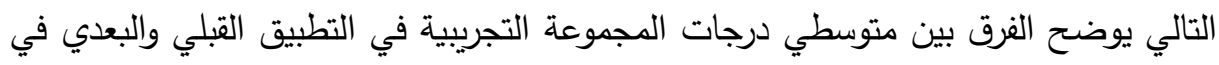
اختبار المعارف البيئية ككل. كما يتضح من نتائج جدول (V) أن قيم (ت) المحسوبة لكل بعد من ابعاد المعارف

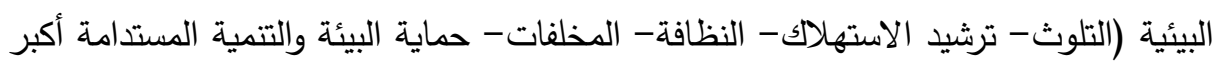

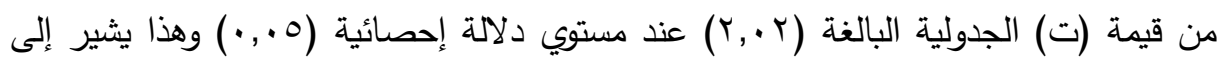
وجود فرق دال إحصائياً بين متوسطي درجات اطفال المجموعة التجريبية في التطبيق التبلي

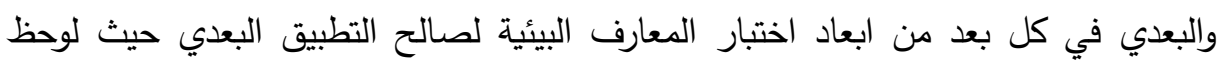

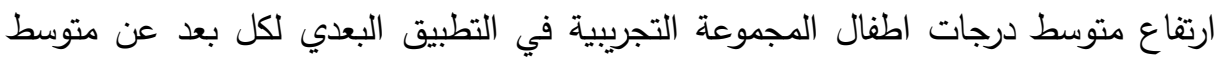

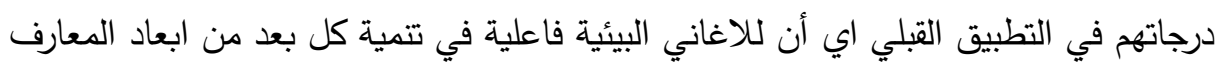
البيئية ككل والثكل التالي يوضح الفرق بين متوسطي درجات المجموعة التجريبية في التطبيق القبلي والبعدي لكل بعد من ابعاد اختبار المعارف البيئية. وللتحقق من تأثير استخدام الاغاني البيئية في تتمية ابعاد اختبار المعارف البيئية لدى لئي

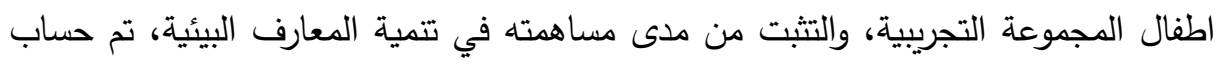

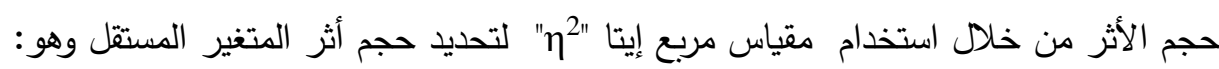
الاغاني البيئية على المتغير التابع وهو : المعارف البيئية. 


$$
\text { مجلة العلوم البيئية }
$$

معهد الدراسات والبحوث البيئية - جامعة عين شمس لئن

رانيا علي محمود وآخرون

جدول (^): قيم مربع ايتا (玍) وقيمة (d) المقابلة لها ومقدار حجم أثر استخدام الاغاني في تتمية المعارف ككل

\begin{tabular}{|c|c|c|c|c|c|}
\hline ملاحظة & قيمة حجم & قيتا مريع & الرربة & قيمة (t) & 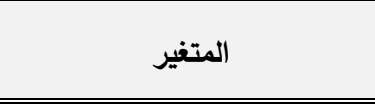 \\
\hline حجم الاثر كبير & $v, \cdot r$ &., 07 & rq & $Y 1,97$ & التلوث \\
\hline حجم الاثر كبير & $V, Y$. &., $0 \mathrm{~V}$ & $r q$ & $r Y, \Sigma q$ & ترشيد الاستهلاكS \\
\hline حجم الاثر كبير & $\varepsilon, 79$ & • ז & $r q$ & $1 \leqslant, 77$ & النظافة \\
\hline حجم الاثر كبير & $r, 91$ & $\cdot, r q$ & rq & $1 Y, \varepsilon \varepsilon$ & المخلفات \\
\hline حجم الاثر كبير & $\Lambda, V Y$ & $\cdot, 74$ & rq & $r V, r Y$ & حماية البيئة والتتمية المستدامة \\
\hline حجم الاثر كبير & $1 \cdot, \wedge 1$ & $\cdot, \mathrm{VO}_{0}$ & $r q$ & $r T, V \leq$ & الدرجة الكلية \\
\hline
\end{tabular}

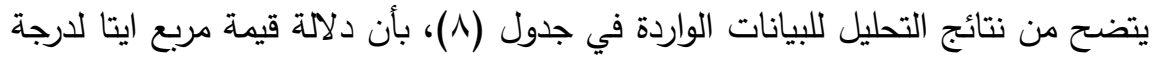

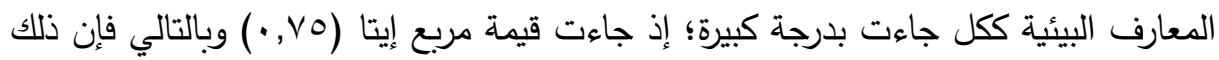
يعد مؤشراً على أن مقدار حجم الأثر (d) جاء بدرجة كبيرة، مما يشير إلى أن استخدام الاغاني البيئي ساهم بدرجة كبيرة في تتمية ابعاد المعارف البيئية ككل. 
مجلة العلوم البيئية

معهد الدراسات والبحوث البيئية - جامعة عين شمس لئئ

رانيا علي محمود وآخرون

نتائج الفرض الثالث: - (و)

جدول (9): يوضح نتائج القياس القبلي والقياس البعدي في المجموعة التجريبية في السلوك

\begin{tabular}{|c|c|c|c|c|c|c|}
\hline الدلالة & 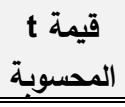 & الانحراف & المتوسطي & العدد & نوع التطبيق & ابعاد السلوك البيئي \\
\hline \multirow{2}{*}{ دال } & \multirow{2}{*}{19,07} & 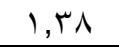 & $\varepsilon, \wedge$. & $\varepsilon \cdot$ & التطبيق القبلي & \multirow{2}{*}{ التلوث } \\
\hline & & $\cdot, \leq 0$ & $9, \wedge r$ & $\varepsilon$ & التطبيق البعدي & \\
\hline \multirow{2}{*}{ دال } & \multirow{2}{*}{ rq,人 } & $1, \leqslant 7$ & מתו & $\varepsilon$ & التطبيق القبلى & \multirow{2}{*}{ ترشيد الاستهلاك } \\
\hline & & $\cdot, \leqslant 1$ & $M, \Lambda$. & $\varepsilon$ & التطبيق البعدي & \\
\hline \multirow{2}{*}{ دال } & \multirow{2}{*}{$10, \leq 0$} & $\cdot, v_{1}$ & $r, .0$ & $\varepsilon$ & التطبيق القبلي & \multirow{2}{*}{ النظافة } \\
\hline & & $\cdot, Y Y$ & $\varepsilon, 90$ & $\varepsilon$ & التطبيق البعدي & \\
\hline \multirow{2}{*}{ دال } & \multirow{2}{*}{10,77} & $\cdot, 7$. & $1, \varepsilon \wedge$ & $\varepsilon$ & التطبيق القبلى & \multirow{2}{*}{ المخلفات } \\
\hline & & $\cdot, \leqslant \wedge$ & r, ז & $\varepsilon$ & التطبيق البعدي & \\
\hline \multirow{2}{*}{ دال } & \multirow{2}{*}{$17, \vee \wedge$} & • & $1, \vee \wedge$ & $\varepsilon$ & التطبيق القبلى & \multirow{2}{*}{ حماية البيئة والتتمية } \\
\hline & &., 01 & $\varepsilon, \Sigma \wedge$ & $\varepsilon$ & التطبيق البعدي & \\
\hline \multirow{2}{*}{ 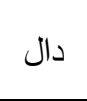 } & \multirow{2}{*}{ rT, } & $r, 90$ & IV,ro & $\varepsilon$ & التطبيق القبلي & \multirow{2}{*}{ الارجة الكلية } \\
\hline & & 1,r & rч, ґᄉ & $\varepsilon$ & التطبيت البعدي & \\
\hline
\end{tabular}

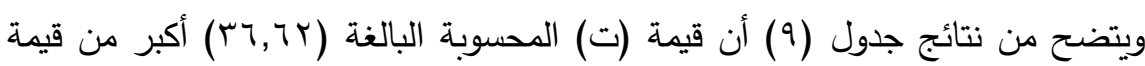

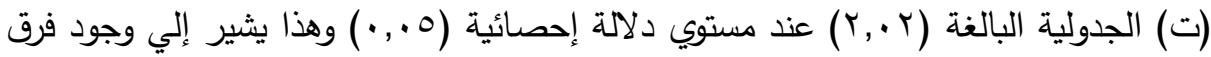

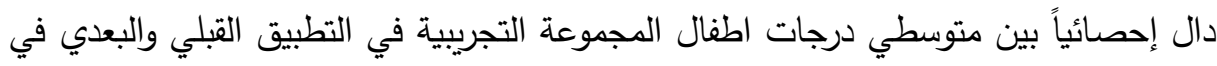
السلوك البيئي ككل لصالح التطبيق البعدي حيث لوحظ ارتفاع متوسط درجات اطفال

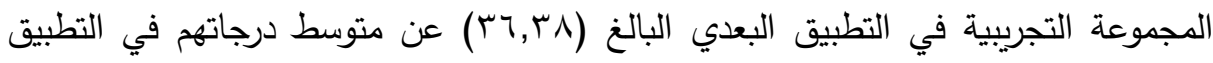

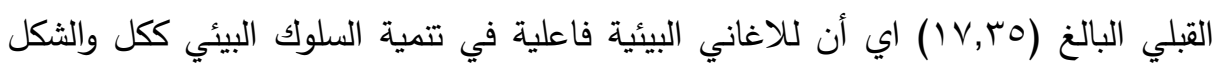

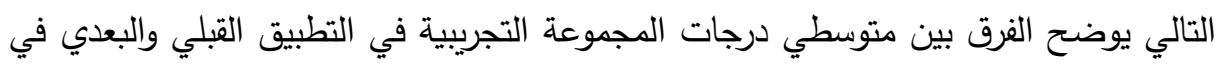

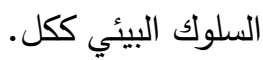


كما يتضح من نتائج جدول (9) أن قيم (ت) المحسوبة لكل بعد من ابعاد السلوك البيئي

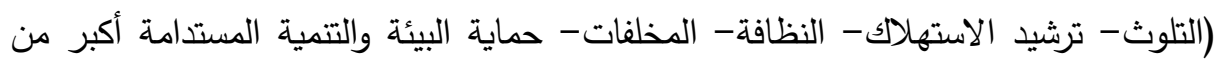

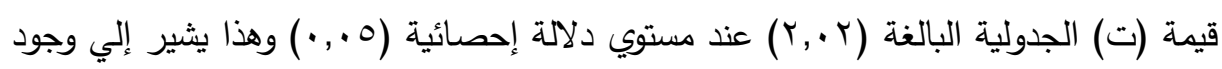
فرق دال إحصائياً بين متوسطي درجات اطفال المجموعة التجريبية في التطبيق القبلي والبعدي التئي

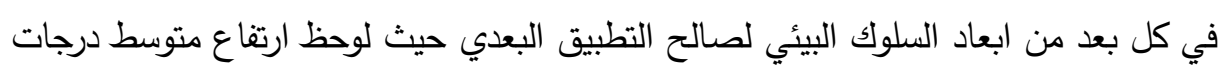
اطفال المجموعة التجريبية في التطبيق البعدي لكل بعد عن متوسط درجاتهم في التطبيق لئي القبلي اي أن للاغاني البيئية فاعلية في تتمية كل بعد من ابعاد السلوك البيئي ككل والثكل

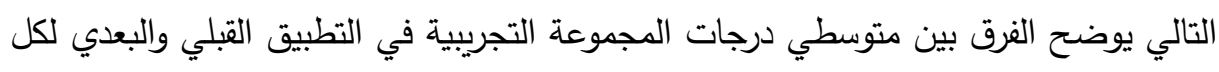
بعد من ابعاد السلوك البيئي.

وللتحقق من تأثير استخدام الاغاني البيئية في تتمية ابعاد السلوك البيئي لدى اطفال

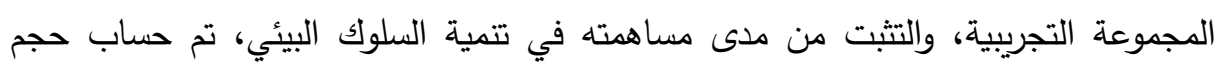

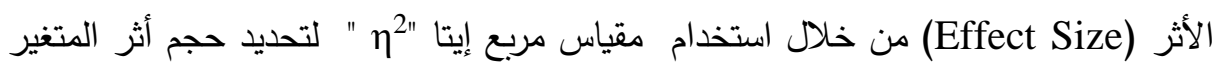
المستقل وهو: الاغاني البيئية على المتغير التابع وهو: السلوك البيئي. جدول (• (1): قيم مربع ايتا (ך) وقيمة (d) المقابلة لها ومقدار حجم أثر استخدام الاغاني

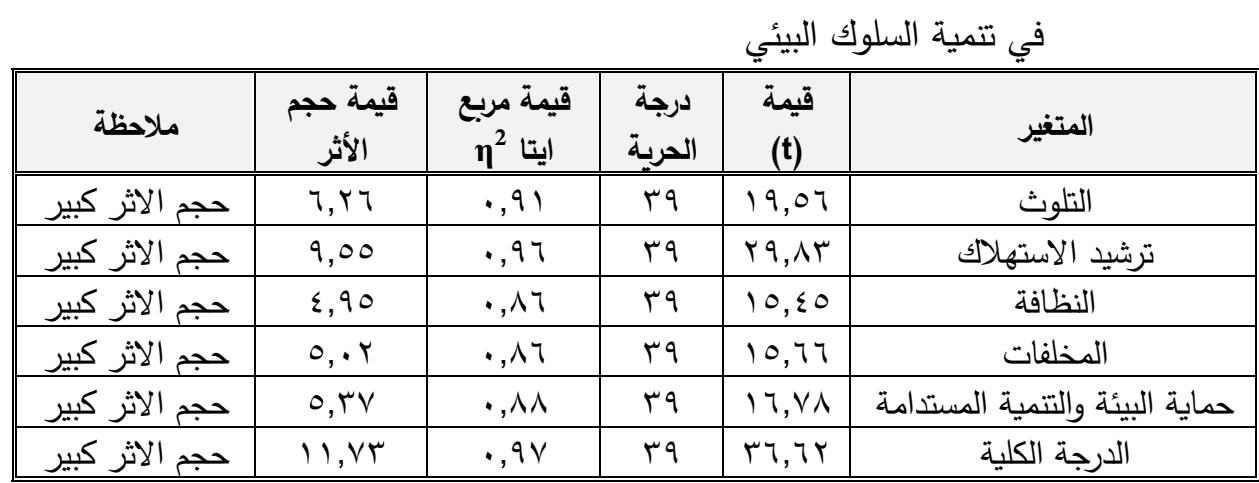

*قيمة حجم الأثر =.A, · فأكثر مؤشر على أن حجم الأثر جاء بدرجة كبيرة

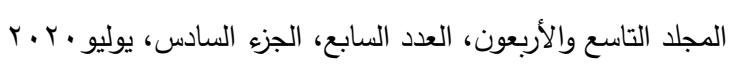


يتضح من نتائج التحليل للبيانات الواردة في الجدول (• ()، بأن دلالة قيمة مربع ايتا

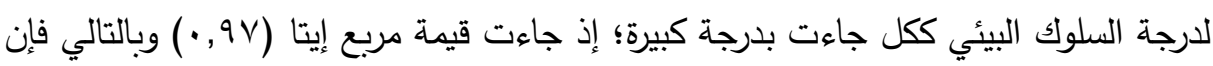
ذلك يعد مؤشراً على أن مقدار حجم الأثر (d) جاء بدرجة كبيرة، مما يثير إلى أن استخدام الاغاني البيئية ساهمت بدرجة كبيرة في تتمية ابعاد السلوك البيئي ككل.

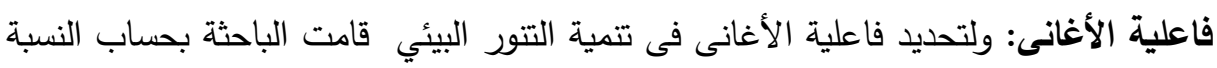

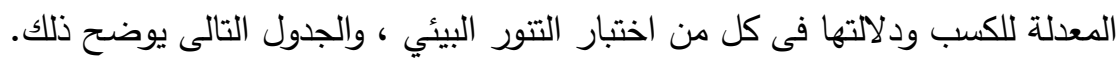
جدول (1 1 (): النسب المعدلة للكسب لبلاك ودلالتها لمقياس التتور البيئي

\begin{tabular}{|c|c|c|c|c|c|}
\hline الإحصائية & النسبة المعدلة & العظمى النهاية & التطبيق البعدى درجات & التطبيق القبلى درجات & الابعاديل الإحصائم \\
\hline إحصائياً & $1, r \wedge$ & $r$. & $r \mu, \varepsilon r$ & 7,01 & المعارف \\
\hline إحصائياً & $1, \varepsilon r$ & rᄉ & M & iv, & السلوك \\
\hline إحصائياً & $1, \Gamma \varepsilon$ & $4 \Lambda$ & $\Delta 9, \wedge$. & rr,qr & المقياس ككل \\
\hline
\end{tabular}

من الجدول السابق يتضح أن النسبة المعدلة للكسب لأبعاد مقياس التنور البيئي

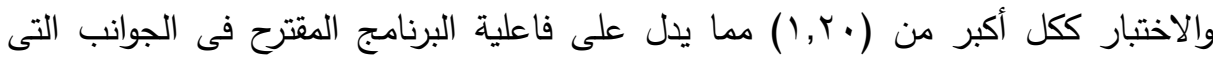
يقيسها مقياس التتور البيئي، وهذه النتائج تؤكد النتائج السابقة. تفسير النتائج: يتضح من خلال نتائج مقياس التتور البيئى أن عرض الأغانى للأطفال، نتج عنه تتمية التتور البيئى لديهم من خلال أبعاد المقياس (المعارف البيئية، السلوك البيئى) ويرجع ذلك إلى التتوع في أثكال وعوامل الجذب فى عرض الأغانى كإستخدام الألوان والمؤثرات السمعية والبصرية وترديد كلمات الأغانى وكان ذلك عاملاً مهماً في جذب التب إنتباه التلاميذ وإستثارة دافعيتهم نحو القضايا البيئية المطروحة، وكذلك إرتباط موضوع الأغانى بحياة الأطفال والبيئة المحيطة بهم، وهذا جعل الأطفال مهتمين بتعلم هذه الموضوعات والإستفادة 206

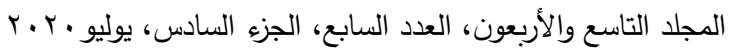

$$
\begin{aligned}
& \text { الترقيم الدولي 0826- ISSN 1110 }
\end{aligned}
$$


منها فى حياتهم، بالإضافة إلى تتاول الأغانى مجموعة من المشكلات والممارسات والتى ترتبط إرتباطاً وثيقاً بالحياة اليومية للأطفال، والتى تتطلب حلولاً متتوعة لمواجهة أخطارها على ملى الإنى

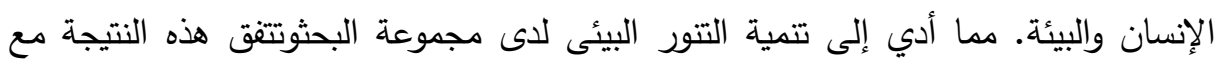
نتائج (Yamamoto, A., 2016)، ودراسة (Silvers, M. B., 2015) ودراسة (Vandrick, J., ودراسة (Bathieu, R., 2015) (2015 وخاصة في فاعلية إستخدام الأغاني البيئية التى تبث على بعض القنوات الفضائية في تتمية التتور البيئى لاى الأطفال.

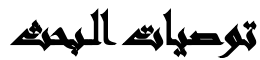

فى ضوء ما قدمه البحث من تصورات نظرية وما توصل إليه من نتائج يوصى بالتالى:

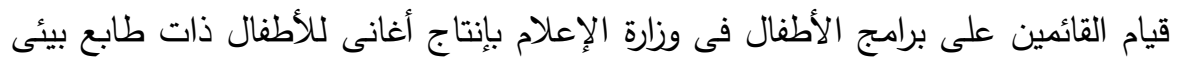
تتبع القطاع الحكومى ويكون لها دورها وتتتج بعنايه ورقابه شديده. تصوير أغانى الأطفال بإسلوب تربوى وجذاب بإستخدام التكنولوجيا الحديثه لجذب إنتباه الأطفال وتوجيههم للسلوكيات السليمه. هالأهتمام بالمكتبه الموسيقيه بالمدرسه وتزويدها بأغانى الأطفال التى تتضمن القيم

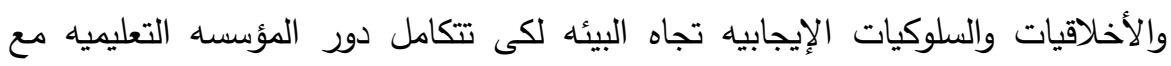
وسائل الإعلام والأسره فى إنثاء جيل يتحلى بالأخلاق والقيم والثعور بالمسئوليه تجاه

بيئته.

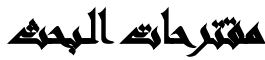

أثارت تلك الدراسه لدى الباحثه بعض الموضوعات التى تصلح أن تكون رؤوساً لموضوعات

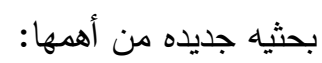

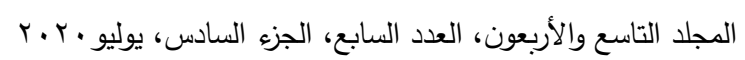

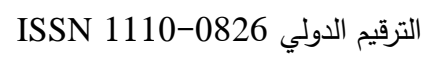




$$
\begin{aligned}
& \text { مجلة العلوم البيئية } \\
& \text { معهد الدراسات والبحوث البيئية - جامعة عين شمس لئ } \\
& \text { رانيا علي محمود وآخرون }
\end{aligned}
$$

• أثر تضمين الأغانى البيئيه فى برامج الأطفال على تتميه الأتجاهات والدافعيه نحو

$$
\text { المشكلات والقضايا البيئيه لدى الأطفال. }
$$

• فاعليه برنامج مقترح قائم على الأغانى البيئيه فى تتميه التفكير التأملى والتحصيل المعرفى

$$
\text { لاى تلاميذ المرحله الإبتدائي. }
$$

• توظيف أدب الأطفال فى تتمية مهارات حل المشكلات البيئيه لدى الأطفال.

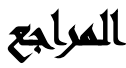

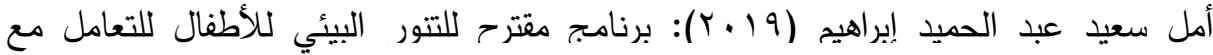

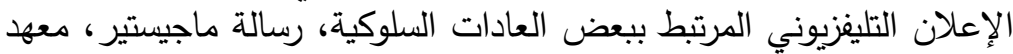

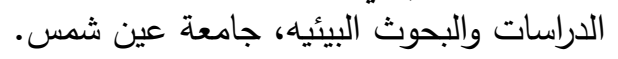

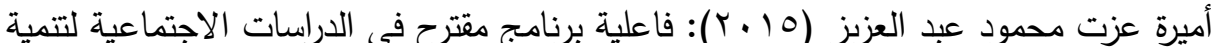
التتور البئي، لدى تلاميذ المرحلة الابتدائية, رسالة ماجستير غير فير منشورة, كلية

$$
\text { التربية, جامعة المنصورة. }
$$

دليلة رفيق ديمترى سلامة (99v ( )): برنامج مقترح للتربية الموسيقية لتقودم سلوكيات الطفل

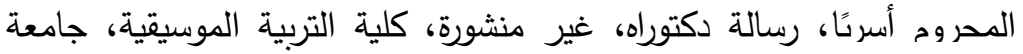

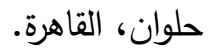

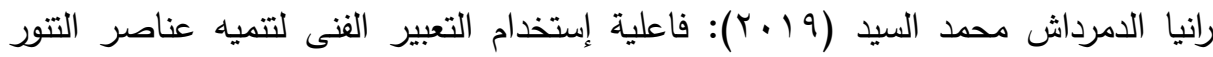
البيئى لاى تلاميذ المرحله الإبتدائيه، رسالة ماجيستير، التئيل معهد الدراسات

$$
\text { والبحوث البيئيه، جامعة عين شمس. }
$$

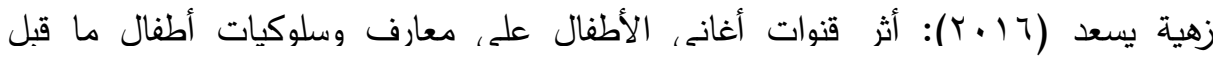

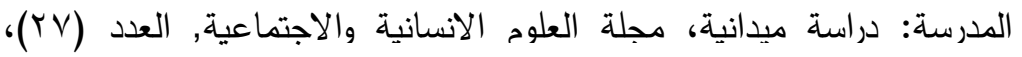

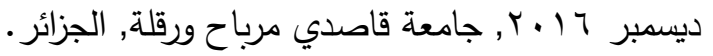

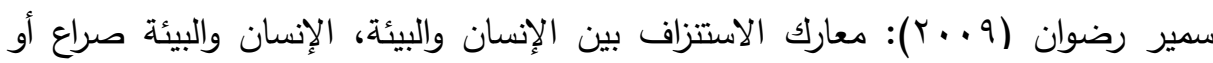
توافق.

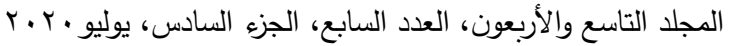

$$
\begin{aligned}
& \text { الترقيم الدولي 0826-0 الانون، }
\end{aligned}
$$


سوزان القليني وصلاح مدكور (r +. r): الإعلام البيئي النظرية والتطبيق، الطبعة الثانية.

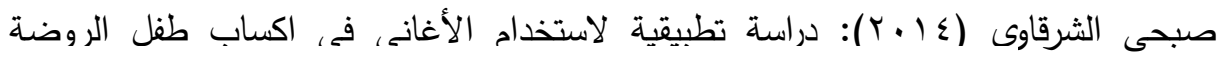

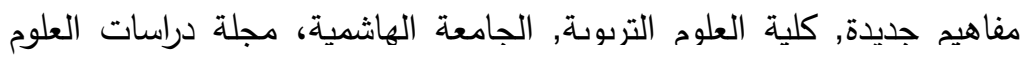
الانسانية والاجتماعية, المجلد (و (ب)، العدد (ب), الأردن.

كمال الدين حسيز ( • ( • ؟): أدب الأطفال والدفاهيم.. الأشكال.. التطبيق. القاهرة، دار العالم

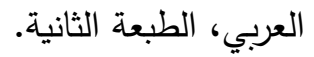

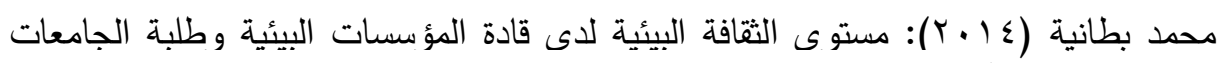

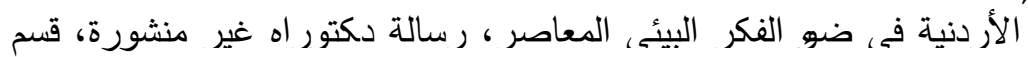
المناهج وطرق التدريس، كلية التربية، جامعة اليرموك، الأردن.

محمود الزيادى (· • (Y): شخصية الطفل والتتشئة الإجتماعية خارج الأسرة، عمان، دار

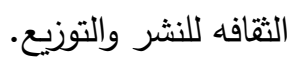

منال عزت حسن شعبان (9 . ب): أثر استخدام أغانه، الأطفال للرواد الأوائل في، تعديل

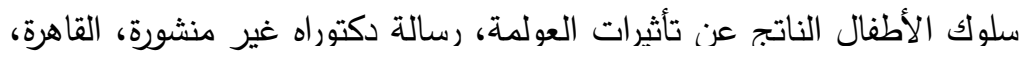
كلية التربية النوعية، قسم التربية الموسيقية، جامعة القاهرة.

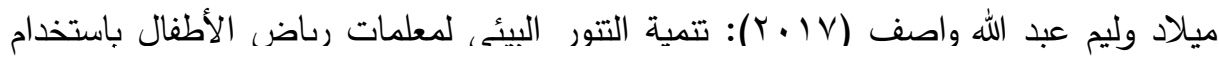

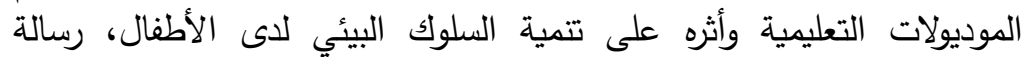

ماجيستير ، معهد الدراسات والبحوث البيئيه، جامعة عين شمس.

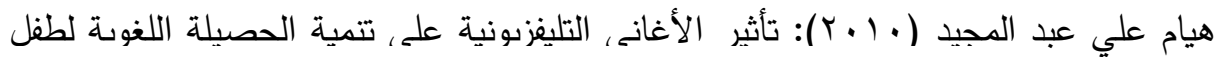

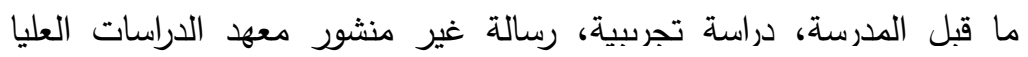
للطفولة، قسم الإعلام وثقافة الطفل.

Akane Yamamoto (2016): The Employment Of Children Environmental Songs In Satellite Channels For Environmental Enlightenment Of Japanese Kindergarten Children. M.A. Thesis, University Of Vermont. P.37.

$$
\begin{aligned}
& \text { المجلد التاسع والأربعون، العدد السابع، الجزء السادس، يوليو • r. }
\end{aligned}
$$

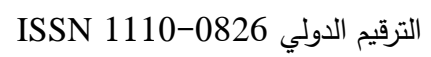




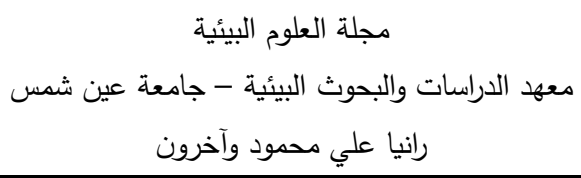

Becky Boudreaux (2016): Environmental Enlightenment Through Songs: The Effectiveness Of 2016 In Environmental Awareness Cultivation For Young Children. M.A. Thesis, University Of New Orleans. P.48.

Bennett, Cindy et al. (2014): Environmental Literacy Plan : Smart Mind Greener Future. Environment And Natural Resources and The N.C. Department Of Public Instruction, North Carolina.

Cottrell, S. P. et al. (1993): General Responsible Environmental Behavior Among Boaters On The Chesapeake Bay. Northeastern Recreation Research Symposium, Saratoga Springs, NY.

Hsu, S. J.: The Effects Of An Environmental Education Program On Responsible Environmental Behavior And Associated Environmental Literacy Variables In Taiwanese College Students. The Journal Of Environmental Education, Vol.35, No.2, 2004. P37- 48.

Jennifer Leigh Publicover (2016): Perspectives on songs, the environment, and sustainability education from recording artists featured on the David Suzuki foundation playlist for the planet, 2011, Master of Environmental Studies, Dalhousie University, Halifax, Nova Scotia, June 2016.

John P. Carroll (2015): The effects of Songs-based environmental education program on children's environmental perceptions, master of science, B.S.F.R., University of Georgia, Athens, Georgia.

Larder, E. (2018): Environmental Song For The Planet: Educator Perceptions Of An Environmental School Song Program For Environmental Literacy, MA Thesis, Royal Roads University.

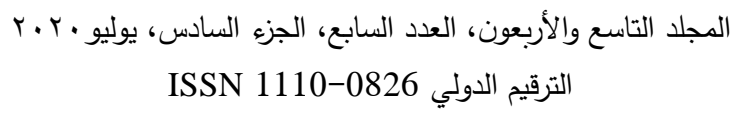




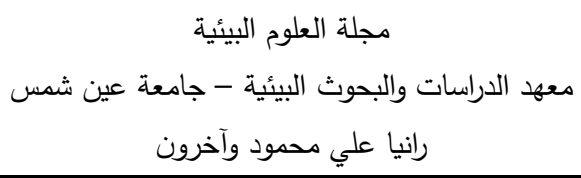

Mathieu, R. (2015): Adopting Cultivation Theory Variables To Determine The Effects Of Environmental Songs At Nickelodeon Channels For Environmental Enlightenment Support For Kindergarteners In Virginia, Phd Thesis, Virginia Polytechnic Institute and State University.

Miguel Laranjo: Environmental Education through Songs: A Case Study in Portugal. Formato Verde, Lda. Journal, Vol. 34, May 2017.

Murphey, Tim (2010): Music And Song, Oxford, Oxford University.

Neumann M. M. and Neumann D. L. (2016): Parent-Child Interactions With Environmental Print. In: Alvarez K (Ed.) Parent-Child Interactions And Relationships: Perceptions, Practices, And Developmental Outcomes. Hauppauge, NY: Nova Science Publishers. P.181.

Roth, C. E. (1992): Environmental Literacy: Its Roots, Evolution, and Directions In The 1990s. Columbus, OH: ERIC Clearinghouse For Science, Mathematics, and Environmental Education.

Russell, T. and Rain R. (1967): The Role Of Foundations and Universities In Conversation California, University Of California, School Foresty.

Sayo OTINGA: The effectiveness of children's songs in developing environmental concepts and behavior among middle school children, Journal of Mass Communication \& Journalism, 2019, 9:3 .

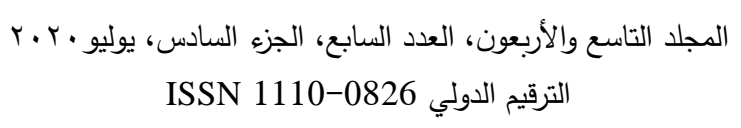




$$
\begin{aligned}
& \text { مجلة العلوم البيئية } \\
& \text { معهد الدراسات والبحوث البيئية - جامعة عين شمس لكس } \\
& \text { رانيا علي محمود وآخرون }
\end{aligned}
$$

Silvers, M. B. (2015): The Uses Of Satellite Channels In Broadcasting Environmental Songs Directed To Kindergarten Children And Effects On Their Environmental Enlightenment In Northeastern Brazil, Phd Thesis, University Of California: Los Angeles, 12 Smart Mind Greener Future", Environment And Natural Resources And The N.C. Department Of Public Instruction, North Carolina

Vandrick, J. (2015): Impact of Songs on Satellite Channels on Awareness and Environmental Enlightenment for Kindergarten Children, MA Thesis, DePaul University.

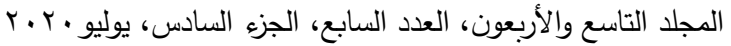

$$
\begin{aligned}
& \text { الترقيم الدولي 0826-0 الانون، }
\end{aligned}
$$




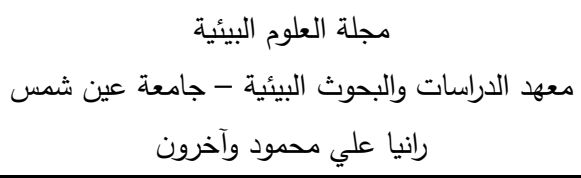

\title{
AN EVALUATIVE STUDY OF ENVIRONMENTAL SONGS IN LIGHT OF THEIR DEVELOPMENT OF THE ELEMENTS OF ENVIRONMENTAL LITERACY AMONG CHILDREN IN SOME SATELLITE CHANNELS
}

\section{Rania A. Mahmoud ${ }^{(1)}$; Hanan M. I. Youssef ${ }^{(2)}$ Hanan E. Zidan ${ }^{(3)}$}

1) Post graduate student at Institute of Environmental Studies and Research, Ain Shams University 2) Faculty of Arts, Ain Shams University 3) Institute of Environmental Studies and Research, Ain Shams University

\begin{abstract}
The aim of this research is to identify the effectiveness of environmental songs in developing environmental literacy for the second-grade primary school pupils. Therefore, the researchers have used the semi-experimental method. A list of elements of environmental literacy that should be developed in children has been prepared, in addition to scale of environmental literacy that includes (environmental knowledge - environmental behavior). Scale of Environmental Literacy has been conducted pre/post presentation of environmental songs to the research group, which consists of (40) items.
\end{abstract}

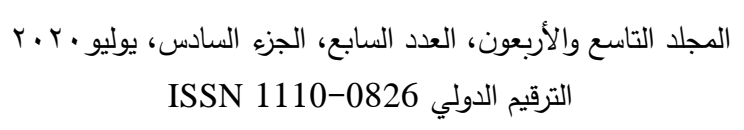




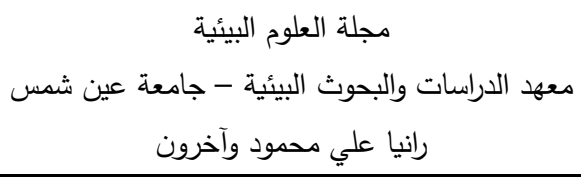

The results indicate the effectiveness of environmental songs in developing environmental literacy for the second-grade primary students, as it shows that there are statistically significant differences at (0.05) significance level between average scores of the research group of the study, regarding the pre/post measurement of the scale of environmental literacy, in favor of the post-application.

The results of the research recommend the necessity of making songs for children to be including new positive values, morals and behaviors associated with how to address the emerging environmental problems, as well as including new environmental problems appropriate to the primary stage and how to deal with them through these songs, integrating also between educational and media institutions outlets to integrate and include environmental songs in the curricula and programs in children television. 